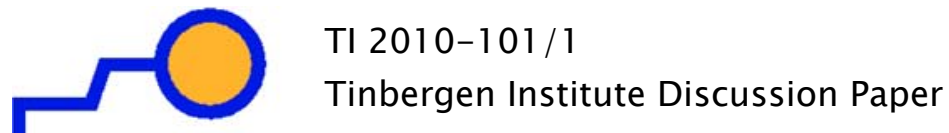 Sovereign Risk and Macroeconomic Fluctuations in an Emerging Market Economy
}

Markus Kirchner

Malte Rieth ${ }^{2}$

${ }^{\prime}$ Faculty of Economics and Business, Dept. of Economics, University of Amsterdam, and Tinbergen Institute;

2 Dept. of Applied Economics, University of Dortmund, and Ruhr Graduate School in Economics. 


\section{Tinbergen Institute}

The Tinbergen Institute is the institute for economic research of the Erasmus Universiteit Rotterdam, Universiteit van Amsterdam, and Vrije Universiteit Amsterdam.

Tinbergen Institute Amsterdam

Roetersstraat 31

1018 WB Amsterdam

The Netherlands

Tel.: +31(0)205513500

Fax: $+31(0) 205513555$

Tinbergen Institute Rotterdam

Burg. Oudlaan 50

3062 PA Rotterdam

The Netherlands

Tel.: + $31(0) 104088900$

Fax: $+31(0) 104089031$

Most TI discussion papers can be downloaded at http://www.tinbergen.nl. 


\title{
Sovereign Risk and Macroeconomic Fluctuations in an Emerging Market Economy*
}

\author{
Markus Kirchner ${ }^{\dagger} \quad$ Malte Rieth ${ }^{\ddagger}$
}

October 2010

\begin{abstract}
This paper assesses the role of sovereign risk in explaining macroeconomic fluctuations in Turkey. We estimate two versions of a simple New Keynesian small open economy model on quarterly data for the period 1994Q3-2008Q2: A basic version and a version augmented by a default premium on government debt due to a perceived risk of sovereign debt default. Model comparisons clearly support the augmented version since it leads to stronger internal propagation and hence smaller shocks are required in order to reconcile the observed dynamics of nominal and real variables, leading to better forecasting performance. The estimated default probability is highly debt-elastic, indicating that default fears are a relevant concern. The results suggest that the augmented model may lead to a better understanding of macroeconomic fluctuations in emerging market economies that are subject to sovereign risk. In terms of policy implications, counterfactual experiments show that both more active monetary policy and stronger fiscal feedbacks from debt on taxes can lead to less volatile inflation and debt dynamics, but higher debt feedbacks on taxation additionally reduce expected default rates.
\end{abstract}

Keywords: Sovereign default risk; Macroeconomic fluctuations; Emerging market economies; Small open economy models; Monetary and fiscal policy

JEL classification: E10; E30; E63; H30

${ }^{*}$ We would like to thank Charles Bos, Markus Hörmann, Falko Juessen, Michael Krause, Alexander Kriwoluzky, Ludger Linnemann, Andreas Schabert and Sweder van Wijnbergen for helpful comments and discussions. We are especially grateful to Nina Budina, Pınar Özyüksel and Hulusi Yüce for support with the data. We also thank seminar and conference participants at Deutsche Bundesbank, the University of Dortmund, the Ruhr Graduate School in Economics, the Dynare conference 2009, the RGS conference 2010 and the 2010 congress of the Society for Computational Economics. Any remaining errors are our own.

${ }^{\dagger}$ University of Amsterdam, Department of Economics, and Tinbergen Institute; address: Roetersstraat 11, 1018 WB Amsterdam, The Netherlands; tel.: +31 (0)20 525 4236; fax: +31 (0)20 525 4254; e-mail: markus.kirchner@uva.nl

${ }^{\ddagger}$ University of Dortmund, Department of Applied Economics, and Ruhr Graduate School in Economics; address: Vogelpothsweg 87, 44227 Dortmund, Germany; tel.: +49 (0)231 755 3105; fax: +31 (0)231 7553069 ; e-mail: malte.rieth@tu-dortmund.de 


\section{Introduction}

This paper investigates the role of sovereign risk in explaining macroeconomic fluctuations in emerging market economies. While there is a growing empirical literature on new openeconomy macroeconomic (NOEM) models for developed countries (see, for example, Lubik and Schorfheide, 2005, 2007, or Justiniano and Preston, 2010), the evidence for less developed countries is still scarce. One possible reason for this lack of studies is that emerging market economies are often characterized by dynamics of nominal and real variables that are difficult to reconcile with standard New Keynesian small open economy models. In particular, many less developed countries are characterized by high inflation rates, high nominal interest rates and a (perceived) risk of sovereign debt default, combined with the inability to borrow from abroad in their own currency. Examples are Argentina, Brazil, Mexico, Russia, or Turkey. In the analysis of business cycles in developed economies sovereign risk is usually neglected. While this might be a good approximation for developed countries, sovereign risk may be an important element of business cycles in less developed countries. We therefore assess the quantitative importance of sovereign risk in explaining the fluctuations of nominal and real variables in Turkey, which is taken as a typical example of an emerging market economy.

We set up a mostly standard model of a small open economy following Galí and Monacelli (2005) but including a fiscal authority. The government borrows in domestic currency at home and in foreign currency abroad. Rigidities in domestic producer prices are the only nominal friction. Unlike Galí and Monacelli (2005) we use CPI inflation stabilization as the central bank's target which is in line with the actual behavior of the Central Bank of the Republic of Turkey (CBRT) (see Ersel and Ozatay, 2008). The government follows a tax rule, as in Schmitt-Grohé and Uribe (2007), with at least some feedback from higher debt levels on taxation. Following Schabert and van Wijnbergen (2010), we argue that the feedback rule may imply perceived infeasible rates of taxation where in such cases the government defaults on (part of) its outstanding debt. The presence of sovereign default believes leads to an endogenous default premium on government debt as a function of total real government liabilities. If the monetary authority follows an active interest rate policy, increases in inflation imply high nominal rates and an associated increase in debt service burden which in turn may lead to higher fears of default. The negative feedback from debt on its return implies that current savings tends to be lower, putting pressure on the real exchange rate, further increasing the need for the monetary authority to raise nominal interest rates. This destabilizing effect of active monetary policy in the presence of fears of default has been 
pointed out by Blanchard (2005) in the context of Brazil.

We outline two variants of the model which differ only with respect to the existence of the expected default rate in the Euler equation. More specifically, the basic model without sovereign risk is a special case of the augmented model with sovereign risk but where the expected default rate in the Euler equation is restricted to equal zero. Then, the model reduces to a standard New Keynesian small open economy model where the level of debt is irrelevant for the dynamics of inflation, the nominal interest rate and consumption.

We estimate both versions of the model on quarterly Turkish data for the period 1994Q32008Q2 using Bayesian methods. We find that the estimated expected default rate is highly debt-elastic, indicating that default fears are a relevant concern. Formal model comparisons between the two models clearly support the proposed modification of the Euler equation in the augmented version. We find that in the basic model, large shocks are required in order to reconcile the observed dynamics of nominal and real variables. In turn, accounting for sovereign risk leads to stronger internal propagation and better forecasting performance. In terms of policy implications, counterfactual experiments show that higher fiscal feedbacks from debt on taxation lead to stable debt and inflation dynamics, by reducing expected default rates. On the other hand, more active monetary policy is also an effective stabilization device for inflation and debt, but it does not reduce expected default rates.

Turkey is an illustrative example to study the role of sovereign risk in emerging market economies. The country was hit by two financial crises in the last decades. The last crisis burst in November 2000 when interest rates on Turkish government bonds shot up, accompanied by a downgrading of Turkey's debt to below investment grade, indicating that fears of sovereign default played an important role. This view is supported by several studies (see Basci and Ekinci, 2005, Aktas, Kaya, and Ozlale, 2005, or Budina and van Wijnbergen, 2008). The presence of sovereign risk and the associated default premia are therefore imminent explanations for the observed variations in nominal interest rates on Turkish debt. 1 Moreover, good data availability in the case of Turkey, compared to many other emerging market economies, means that we can estimate the model on a relatively large number of macroeconomic time series for a relatively long sample.

Our study is related to several strands of literature in addition to the above cited literature on the estimation of NOEM models. First, several studies explore the role of different driving forces of real business cycle in small open economy models for less developed countries. Aguiar

\footnotetext{
${ }^{1}$ Recent concerns about fiscal solvency in euro area countries such as Greece, Portugal or Spain suggest that our results may also have implications for developed economies, both in terms of business cycle analysis and policy recommendations.
} 
and Gopinath (2007) argue that a stochastic productivity trend - rather than transitory fluctuations around a stable trend - goes a long way towards explaining several empirical regularities of emerging market economies and in particular the high volatility of consumption relative to output. Neumeyer and Perri (2005) and Uribe and Yue (2006) show that foreign interest rate shocks amplified by financial frictions (for example working capital requirements) are consistent with the counter-cyclicality of interest rates and output in emerging market economies. Chang and Fernández (2010) encompass both approaches into one model and evaluate the fit of each model using Bayesian methods. Formal model comparisons attribute a larger role to interest rates and financial frictions in generating aggregate fluctuations as opposed to permanent technology shocks. Our analysis is partly inspired by this finding on the importance of interest rates in understanding fluctuations in emerging market economies, but we assess their role in a model with nominal frictions.

Second, models of monetary policy start from the assumption that the central bank controls the short rate as its policy instrument. It is linked to the economy through the consumption Euler equation. Thus, standard New Keynesian models imply that movements in the short rate are associated one-for-one with movements in the expected growth of the marginal utility of the representative consumer and expected inflation. However, the empirical shortcomings of the Euler equation have lead researchers to include ad hoc risk-premium shocks into the Euler equation in both closed and open economy models (see, for example, Adolfson, Laséen, Lindé, and Villani, 2007; Smets and Wouters, 2007; Justiniano and Preston, 2010). We focus instead on internal propagation mechanisms in order to improve both the forecasting performance of the current generation of models and their usefulness for policy analysis.

Third, based on the seminal contribution of Eaton and Gersovitz (1981), many papers analyze the role of strategic default of the government and fluctuations in emerging economies. Most prominently, Arellano (2008) focuses on the terms of international loans which are endogenous to domestic fundamentals and depend on the incentives to default in order to explain co-movements between real interest rates and output. While this literature focuses on the strategic incentives for the government to default in order to smooth consumption, in our model their is no strategic motive for the government which follows a simple fiscal feedback rule. Default premia are instead determined by investors' beliefs that infeasible rates of taxation implied by this rule force the government to default on its debt.

The remainder of the paper is organized as follows. In the next section we lay out the model. In Section 3 we discuss the empirical implementation and in Section 4 we present the 
results. In particular, we compare the basic and the augmented model in terms of business cycle moments, forecasting performance, marginal data densities and variance decompositions, and we implement counterfactual experiments based on the estimated augmented model. Section $[5]$ concludes.

\section{Model Description}

In this section we set up a small open economy model with sticky prices based on Galí and Monacelli (2005). The model considers expectations about sovereign default, following Schabert and van Wijnbergen (2010). We allow for foreign currency denominated debt in order to provide a realistic description of the conduct of fiscal policy in Turkey. While the Turkish government can borrow from domestic households in terms of its own currency, it cannot borrow from abroad in Turkish lira. Eichengreen and Hausmann (1999) and Eichengreen, Hausmann, and Panizza (2007) call this inability the 'original sin', which typically characterizes emerging market economies. Due to the presence of foreign currency denominated debt, changes in the real exchange rate have a direct impact on expected sovereign default rates.

\subsection{The public sector}

The public sector consists of a government and a central bank. The price of domestic bonds is set by the central bank, and since government bonds are subject to perceived default risk, the central bank's policy instrument is an interest rate on an asset which exhibits a contingent pay-off. Thus, even if one interprets the policy instrument as a short-term interest rate, it carries a risk component that will be reflected in equilibrium (see Schabert and van Wijnbergen, 2006) 2

\subsubsection{Fiscal policy}

The government issues one-period discount bonds denominated in domestic currency $B_{H, t}$, which are held by domestic households, and bonds denominated in foreign currency $B_{F, t}$, which are held by foreign households 3 It also levies lump-sum taxes $P_{t} \tau_{t}$ on domestic households and it purchases domestic goods $P_{H, t} g_{t}$, where $P_{t}$ and $P_{H, t}$ denote the consumer price

\footnotetext{
${ }^{2}$ In fact, in his discussion of Blanchard (2005), Loyo (2005) argues that even an overnight rate (specifically, the Brazilian Selic) contains a risk premium.

${ }^{3}$ Throughout, nominal (real) variables are denoted by capital (lower) letters, asterisks denote foreign variables and variables without time subscript denote non-stochastic steady state values.
} 
level and the price of domestically produced goods, respectively. The assumption that government purchases are fully allocated to domestically produced goods seems reasonable in view of empirical evidence for OECD countries of a strong home bias in government procurement, over and above that observed in private consumption (see e.g. Trionfetti, 2000; Brulhart and Trionfetti, 2004). The central bank sets the domestic currency price $1 / R_{H, t}$ of domestic bonds, whereas the foreign currency price $1 / R_{F, t}$ of foreign bonds is endogenously determined in equilibrium.

The government is assumed to follow a simple tax feedback rule, adjusting lump-sum taxes (net of savings of default) in response to the outstanding stock of debt,

$$
P_{t} \tau_{t}=\kappa\left(B_{H, t-1}+X_{t} B_{F, t-1}\right)+P_{t} \exp \left(\varepsilon_{\tau, t}\right), \quad \varepsilon_{\tau, t} \sim N I D\left(0, \sigma_{\tau}^{2}\right)
$$

where $\varepsilon_{\tau, t}$ is a fiscal policy shock or implementation error in the conduct of policy, and $X_{t}$ denotes the domestic currency price of one unit of foreign currency. Following Bohn (1992), a tax rule of this type ensures fiscal solvency as long as $\kappa>0$, for any finite initial level of debt. However, it may imply politically infeasible levels of taxation as discussed next.

\subsubsection{Investors' beliefs}

Following Schabert and van Wijnbergen (2010), according to domestic and foreign investors' beliefs, the government defaults when debt service would demand a politically infeasible level of taxation $\bar{T}$. Lenders do not know the exact value of $\bar{T}$, but they have a prior on its distribution, $f(\bar{T})$. Given that tax revenues are set according to (11), the perceived probability of default $\delta_{t}$ then equals the probability that the tax rule implies a level of $\tau_{t}$ exceeding $\bar{T}$ :

$$
\delta_{t}=\int_{0}^{\tau_{t}} f(\bar{T}) d \bar{T}
$$

where $\tau_{t}=\kappa\left(B_{H, t-1}+X_{t} B_{F, t-1}\right) / P_{t}+\exp \left(\varepsilon_{\tau, t}\right)$. For a differentiable distribution function $f(\cdot)$ the impact of total real debt

$$
b_{t}=\left(B_{H, t-1}+X_{t} B_{F, t-1}\right) / P_{t}=b_{H, t-1} \pi_{t}^{-1}+q_{t} b_{F, t-1} \pi_{t}^{*-1},
$$

where $b_{t}$ is not predetermined due to the presence of the exchange rate, on the probability of default is given by

$$
\frac{\partial \delta_{t}(\cdot)}{\partial b_{t}}=\kappa f\left(\kappa b_{t}\right)>0
$$


Thus, the perceived default probability strictly increases with the real value of total debt. For the local analysis of the model we use the product of the default elasticity with respect to the real value of total debt evaluated at the steady state with the ratio $\frac{b_{H} / \pi}{1-\delta}$, where $\delta=\delta(b)<1$ :

$$
\Phi=\frac{b_{H} / \pi}{1-\delta}\left(\left.\frac{\partial \delta_{t}(\cdot)}{\partial b_{t}}\right|_{b_{t}=b}\right)
$$

We refer to $\Phi$ as the default elasticity, and we treat it as a structural parameter in the empirical implementation. Note that $\Phi>0$ if the steady state satisfies $b_{H} / \pi>0$ (see 3) 4 This structure of the default elasticity has broad empirical support; see, for instance, Edwards (1994), Cantor and Packer (1996), Min (1998), Eichengreen and Mody (1998) and Ferucci (2003).

In order to pin down the division of total debt among domestic debt and foreign debt, which is under the discretion of the government, we assume that the government issues foreign currency denominated debt as a time-varying fraction $f_{t} \geq 0$ of domestic debt:

$$
X_{t} \frac{B_{F, t}}{R_{F, t}}=f_{t} \frac{B_{H, t}}{R_{H, t}}
$$

where $f_{t}$ follows an $\mathrm{AR}(1)$ process in logs:

$$
\log \left(f_{t} / \bar{f}\right)=\rho_{f} \log \left(f_{t-1} / \bar{f}\right)+\varepsilon_{f, t}, \quad \varepsilon_{f, t} \sim N I D\left(0, \sigma_{f}^{2}\right)
$$

We assume that the savings of default $\delta_{t}\left(B_{H, t-1}+X_{t} B_{F, t-1}\right)$ are handed out in a lumpsum fashion to domestic households. Given the specification (2), the period-by-period expected government budget constraint for any period $t$ reads:

$$
\begin{aligned}
\frac{B_{H, t}}{R_{H, t}}+X_{t} \frac{B_{F, t}}{R_{F, t}}+P_{t} & \tau_{t}-\delta_{t}\left(B_{H, t-1}+X_{t} B_{F, t-1}\right) \\
& =P_{H, t} g_{t}+\left(1-\delta_{t}\right)\left(B_{H, t-1}+X_{t} B_{F, t-1}\right)
\end{aligned}
$$

where $g_{t}$ follows an $\mathrm{AR}(1)$ process in logs:

$$
\log \left(g_{t} / \bar{g}\right)=\rho_{g} \log \left(g_{t-1} / \bar{g}\right)+\varepsilon_{g, t}, \quad \varepsilon_{g, t} \sim N I D\left(0, \sigma_{g}^{2}\right) .
$$

\footnotetext{
${ }^{4}$ Appendix $\left[\right.$ shows that, while we compute $\frac{\partial \delta_{t}(\cdot)}{\partial b_{t}}$ at $b_{t}=b$, the log-linearization of the model's equilibrium conditions and simplification leads to an expression for $\Phi$ in terms of $b_{H} / \pi$. This expression implies a positive default premium if the real stock of Turkish lira debt is positive in steady state.
} 


\subsubsection{Monetary policy}

The central bank sets the domestic currency price of domestic bonds according to a CPI based Taylor rule:

$$
\frac{R_{H, t}}{R_{H}}=\left(\frac{\pi_{t}}{\pi}\right)^{\alpha_{\pi}} \exp \left(\varepsilon_{R, t}\right), \quad \varepsilon_{R, t} \sim N I D\left(0, \sigma_{R}^{2}\right),
$$

where the interest rate and inflation targets of the central bank are assumed to be consistent with steady state values. Before the economic reforms introduced in 2001, the central bank actually followed a crawling peg exchange rate targeting strategy (see Gormez and Yilmaz, 2007). In order to account for this fact, we check in Section 4.3 the sensitivity of the estimation results to the introduction of an exchange rate stabilization term in the Taylor rule. Since we are primarily interested in the interaction between an inflation targeting monetary authority and fiscal policy we do not include the output gap into the Taylor rule. Moreover, since visual inspection of the data on the nominal interest shows that interest rate smoothing seemed not to be a primary goal of the CBRT - at least for the first half of the sample - we do not include a smoothing term into the Taylor rule. Finally, specifying the most simplest Taylor rule helps achieving better identification of the parameters of interest in the estimation step by reducing the number of estimated parameters to a necessary minimum 5 Finally, define the nominal rate of depreciation as

$$
\pi_{X, t}=\frac{X_{t}}{X_{t-1}}=\left(\frac{q_{t}}{q_{t-1}}\right) \frac{\pi_{t}}{\pi_{t}^{*}}
$$

where $q_{t}=X_{t} P_{t}^{*} / P_{t}$ denotes the real exchange rate.

\subsection{The private sector}

\subsubsection{Domestic households}

The domestic economy is inhabited by a continuum of infinitely lived households, with identical asset endowments and identical preferences. A representative domestic household chooses consumption $c_{t}$, hours worked $n_{t}$, and the asset portfolio described below, so as to maximize

$$
E_{0} \sum_{t=0}^{\infty} \beta^{t}\left(\exp \left(\varepsilon_{c, t}\right) \frac{c_{t}^{1-\sigma}}{1-\sigma}-\frac{n_{t}^{1+\eta}}{1+\eta}\right), \quad \sigma>0, \quad \eta \geq 0,
$$

\footnotetext{
${ }^{5}$ In Section 4.3 we check the sensitivity of our results to an inclusion of an output gap and smoothing term into the Taylor rule.
} 
where $\beta \in(0,1)$ denotes the time discount factor, $\sigma$ is the inverse of the intertemporal elasticity of substitution in consumption, $\eta$ denotes the inverse of the Frisch elasticity of labor supply and $\varepsilon_{c, t} \sim \operatorname{NID}\left(0, \sigma_{c}^{2}\right)$ is a demand shock 6

We assume that domestic households only invest in domestic currency bonds and in a complete set of state-contingent securities which are traded internationally. Let $\Gamma_{t, t+1}$ denote the stochastic discount factor for a one-period ahead nominal payoff $S_{t+1}$ in foreign currency. Optimization occurs subject to a no-Ponzi game condition and the perceived flow budget constraint, which takes into account the households' default beliefs,

$$
P_{t} c_{t}+P_{t} \tau_{t}+E_{t}\left(X_{t} \Gamma_{t, t+1} S_{t+1}\right)+\frac{B_{H, t}}{R_{H, t}} \leq X_{t} S_{t}+\left(1-\delta_{t}\right) B_{H, t-1}+P_{t} w_{t} n_{t}+\Sigma_{t}
$$

for given initial wealth endowments $B_{H,-1}$ and $S_{0}$. Here, $w_{t}$ is the real wage rate and $\Sigma_{t}$ collects dividends received from the ownership of firms, which are both taken as given by the household.

The representative household's consumption basket is an aggregate of domestically produced goods $c_{H, t}$ and goods of foreign origin $c_{F, t}$ :

$$
c_{t}=\gamma\left(c_{H, t}\right)^{1-\vartheta}\left(c_{F, t}\right)^{\vartheta}
$$

where $\vartheta \in[0,1]$ denotes the import share and $\gamma=\left[\vartheta^{\vartheta}(1-\vartheta)^{1-\vartheta}\right]^{-1}$. The optimal allocation of consumption among $c_{H, t}$ and $c_{F, t}$ yields the demand functions

$$
c_{H, t}=(1-\vartheta)\left(\frac{P_{H, t}}{P_{t}}\right)^{-1} c_{t}, \quad c_{F, t}=\vartheta\left(\frac{P_{F, t}}{P_{t}}\right)^{-1} c_{t}
$$

where $P_{H, t}$ and $P_{F, t}$ are the prices of domestic and foreign goods, respectively. The composite consumption price index $(\mathrm{CPI})$ is

$$
P_{t}=P_{H, t}^{1-\vartheta} P_{F, t}^{\vartheta}
$$

The first-order conditions from the maximization of (5) subject to (6) are

$$
\begin{aligned}
\lambda_{t} & =\exp \left(\varepsilon_{c, t}\right) c_{t}^{-\sigma} \\
n_{t}^{\eta} & =\lambda_{t} w_{t} \\
\lambda_{t} & =R_{H, t} \beta E_{t}\left[\left(1-\delta_{t+1}\right) \lambda_{t+1} \pi_{t+1}^{-1}\right]
\end{aligned}
$$

\footnotetext{
${ }^{6}$ We do not specify an $\operatorname{AR}(1)$ process for $\varepsilon_{c, t}$ in order to reduce the amount of exogenous persistence in the consumption Euler equation (see below).
} 


$$
\Gamma_{t, t+1}=\beta \frac{X_{t+1} \lambda_{t+1}}{X_{t} \lambda_{t}} \pi_{t+1}^{-1},
$$

where $\lambda_{t}$ denotes the Lagrangian multiplier associated with (6),$\pi_{t}=P_{t} / P_{t-1}$ denotes the gross CPI inflation rate. The budget constraint holds with equality and the transversality conditions are satisfied.

The first equation equates the marginal utility gain of additional consumption and the shadow price of wealth. The second equation says that the marginal rate of substitution has to equal the real wage. The last two equations equate the intertemporal terms of trade using the available assets. Combining (10) and (11), it follows that higher expected default leads investors to demand a higher interest rate on domestic bonds for a given expected rate of nominal depreciation and a given stochastic discount factor:

$$
R_{H, t}^{-1}=E_{t}\left[\left(1-\delta_{t+1}\right) \pi_{X, t+1}^{-1} \Gamma_{t, t+1}\right]
$$

\subsubsection{Foreign households}

The foreign economy is inhabited by a continuum of infinitely lived households with identical asset endowments, which have qualitatively the same preferences as domestic households. A representative foreign household's demand for domestically produced consumption goods $c_{H, t}^{*}$ satisfies

$$
c_{H, t}^{*}=\vartheta^{*}\left(\frac{P_{H, t}^{*}}{P_{t}^{*}}\right)^{-1} c_{t}^{*},
$$

where $\vartheta^{*} \in(0,1)$ and $c_{t}^{*}$ is aggregate foreign consumption. The foreign households invest in state-contingent securities $S_{t}$ and foreign currency denominated bonds issued by the domestic government $B_{F, t}$. The first order conditions are given by

$$
\begin{aligned}
\Gamma_{t, t+1} & =\beta \frac{\lambda_{t+1}^{*}}{\lambda_{t}^{*}} \pi_{t+1}^{*-1} \\
\lambda_{t}^{*} & =R_{F, t} \beta E_{t}\left[\left(1-\delta_{t+1}\right) \lambda_{t+1}^{*} \pi_{t+1}^{*-1}\right]
\end{aligned}
$$

where $\lambda_{t}^{*}=c_{t}^{*-\sigma}$. Note that (13) (together with 11) allows perfect international risk sharing (see below). Since the foreign economy is exogenous to the domestic economy, we assume for simplicity that foreign consumption and foreign inflation are determined according to an (identified) vector autoregression of order 4, specified in logs (see Section 3.3). 


\subsubsection{Final goods producers}

The final domestic good $y_{H, t}$ is assembled by a perfectly competitive final goods sector from intermediate goods $y_{H, t}^{i}$, for $i \in[0,1]$, through the technology

$$
y_{H, t}=\left(\int_{0}^{1}\left(y_{H, t}^{i}\right)^{\frac{\epsilon-1}{\epsilon}} d i\right)^{\frac{\epsilon}{\epsilon-1}},
$$

where $\epsilon$ denotes the elasticity of substitution among intermediate goods.

The final goods producer maximizes profits over input demands taking as given all intermediate goods prices $P_{H, t}^{i}$ and the final goods price $P_{H, t}$ :

$$
\max _{y_{H, t}^{i}} P_{H, t} y_{H, t}-\int_{0}^{1} P_{H, t}^{i} y_{H, t}^{i} d i
$$

which yields the input demand functions

$$
y_{H, t}^{i}=\left(\frac{P_{H, t}^{i}}{P_{H, t}}\right)^{-\epsilon} y_{H, t} \text { for all } i
$$

where we have used the zero profit condition in the final goods sector, i.e. $P_{H, t} y_{H, t}=$ $\int_{0}^{1} P_{H, t}^{i} y_{H, t}^{i} d i .7$

The price index for domestic goods $P_{H, t}$ follows from substituting (15) into the zero profit condition stated above:

$$
P_{H, t}=\left(\int_{0}^{1}\left(P_{H, t}^{i}\right)^{1-\epsilon} d i\right)^{\frac{1}{1-\epsilon}} .
$$

\subsubsection{Intermediate goods producers}

Intermediate goods production is done by a continuum of monopolistically competitive firms. Each firm $i$ uses the technology

$$
y_{H, t}^{i}=a_{t} n_{t}^{i},
$$

${ }^{7}$ The first-order conditions corresponding to the solution of the final goods producer's profit maximization problem are

$$
P_{H, t}^{i}=P_{H, t}\left(y_{H, t}^{i}\right)^{\frac{\epsilon-1}{\epsilon}-1}\left(\int_{0}^{1}\left(y_{H, t}^{i}\right)^{\frac{\epsilon-1}{\epsilon}} d i\right)^{\frac{\epsilon}{\epsilon-1}-1} \quad \text { for all } i .
$$

Dividing the first-order conditions for two types of goods $i$ and $j$ by each other gives

$$
P_{H, t}^{i} y_{H, t}^{i}=P_{H, t}^{j}\left(y_{H, t}^{j}\right)^{\frac{1}{\epsilon}}\left(y_{H, t}^{i}\right)^{\frac{\epsilon-1}{\epsilon}} .
$$

Integrating over all intermediate goods yields

$$
\int_{0}^{1} P_{H, t}^{i} y_{H, t}^{i} d i=P_{H, t}^{j}\left(y_{H, t}^{j}\right)^{\frac{1}{\epsilon}} y_{H, t}^{\frac{\epsilon-1}{\epsilon}}=P_{H, t} y_{H, t},
$$

where the last equality follows from the zero profit condition. 
where $a_{t}$ is common factor productivity which follows an AR(1) process in logs

$$
\log a_{t}=\rho_{a} \log a_{t-1}+\varepsilon_{a, t}, \quad \varepsilon_{a, t} \sim N I D\left(0, \sigma_{a}^{2}\right) .
$$

Intermediate goods producers solve a two-stage problem. In the first stage, taking the input price $w_{t}$ as given, firms hire labor in order to minimize costs independently of the output price $P_{H, t}^{i}$ :

$$
\min _{n_{t}^{i}} P_{t} w_{t} n_{t}^{i} \quad \text { s.t. } \quad y_{H, t}^{i}=a_{t} n_{t}^{i} .
$$

Assuming an interior solution, the first-order conditions are

$$
P_{t} w_{t}=M C_{t}^{i} a_{t} \text { for all } i
$$

where $M C_{t}^{i}$ denotes the Lagrangian multiplier associated with the technology constraint, i.e. nominal marginal costs. Marginal costs are seen to be common across domestic firms, $M C_{t}^{i}=$ $M C_{t}$, since all firms face the same input prices and use the same technology. Expressing real marginal costs in terms of domestic prices, $m c_{t}=M C_{t} / P_{H, t}$, then yields the labor demand function

$$
w_{t}=\frac{P_{H, t}}{P_{t}} m c_{t} a_{t}
$$

In the second stage of the intermediate goods producers' problem, given real marginal costs, they choose prices $P_{H, t}^{i}$ in order to maximize discounted real profits. Following Calvo (1983) and Yun (1996), in each period a fraction $1-\phi$ of randomly selected firms is allowed to set a new price $\check{P}_{H, t}^{i}=\check{P}_{H, t}$, by symmetry. The remaining firms change their prices along with steady state producer price inflation $\pi_{H}$. Each firm $i$ which receives permission to optimally reset its price maximizes the expected sum of discounted profits subject to the demand function (15):

$$
\begin{aligned}
& \max \quad E_{t} \sum_{s=0}^{\infty} \phi^{s} X_{t} \Gamma_{t, t+s}\left[P_{H, t}^{i}-P_{H, t+s} m c_{t+s}\right] y_{H, t+s}^{i} \\
\text { s.t. } & y_{H, t}^{i}=\left(\frac{P_{H, t+s}^{i}}{P_{H, t+s}}\right)^{-\epsilon} y_{H, t+s},
\end{aligned}
$$

where $P_{H, t+s}^{i}=\check{P}_{H, t} \pi_{H}^{s} \quad$ for $s=1,2, \ldots$ 
The first-order condition is

$$
0=E_{t} \sum_{s=0}^{\infty} \phi^{s} X_{t} \Gamma_{t, t+s} y_{H, t+s}^{i}\left[(1-\epsilon) \pi_{H}^{s} \check{P}_{H, t}+\epsilon P_{H, t+s} m c_{t+s}\right]
$$

The price index of domestic goods follows as

$$
P_{H, t}=\left[(1-\phi) \check{P}_{H, t}^{1-\epsilon}+\phi\left(\pi_{H} P_{H, t-1}\right)^{1-\epsilon}\right]^{\frac{1}{1-\epsilon}} .
$$

\subsection{Market clearing}

Market clearing requires that the demand for labor services is equal to labor supply:

$$
\int_{0}^{1} n_{t}^{i} d i=n_{t}
$$

Integrating $y_{H, t}^{i}=a_{t} n_{t}^{i}$ over all $i$, it then follows that

$$
\int_{0}^{1} y_{H, t}^{i} d i=a_{t} n_{t}
$$

or, using the demand functions (15):

$$
y_{H, t} v_{t}=a_{t} n_{t},
$$

where $v_{t}=\int_{0}^{1}\left(\frac{P_{H, t}^{i}}{P_{H, t}}\right)^{-\epsilon} d i$ is a price dispersion term.

We assume the domestic economy to be small relative to the foreign economy, implying that the foreign producer price level $P_{F, t}^{*}$ is identical to the foreign consumption price index $P_{t}^{*}$. Furthermore, the law of one price is assumed to hold separately for each good such that $P_{F, t}=X_{t} P_{F, t}^{*}$ and $P_{H, t}=X_{t} P_{H, t}^{*}$, where $P_{H, t}^{*}$ is the price of domestic goods expressed in foreign currency. Using (7), foreign demand for domestic goods (12) can then be re-written as

$$
c_{H, t}^{*}=\vartheta^{*} q_{t}^{\frac{1}{1-\vartheta}} c_{t}^{*}
$$

and domestic demand $c_{H, t}=(1-\vartheta)\left(\frac{P_{H, t}}{P_{t}}\right)^{-1} c_{t}$ can be re-written as

$$
c_{H, t}=(1-\vartheta) q_{t}^{\frac{\vartheta}{1-\vartheta}} c_{t}
$$

where we have used that $\frac{P_{H, t}}{P_{t}}=\left(\frac{P_{F, t}}{P_{t}}\right)^{-\frac{\vartheta}{1-\vartheta}}=\left(\frac{X_{t} P_{t}^{*}}{P_{t}}\right)^{-\frac{\vartheta}{1-\vartheta}}=q_{t}^{-\frac{\vartheta}{1-\vartheta}}$. 
Goods market clearing requires that aggregate supply equals aggregate demand:

$$
y_{H, t}=c_{H, t}+c_{H, t}^{*}+g_{t} .
$$

Using the demand functions, the goods market clearing condition can be re-written as

$$
y_{H, t}=(1-\vartheta) q_{t}^{\frac{\vartheta}{1-\vartheta}} c_{t}+\vartheta^{*} q_{t}^{\frac{1}{1-\vartheta}} c_{t}^{*}+g_{t}
$$

Further, the CPI inflation rate can be expressed in terms of producer price inflation as follows:

$$
\pi_{t}=\pi_{H, t}\left(q_{t} / q_{t-1}\right)^{\frac{\vartheta}{1-\vartheta}} \text { for all } t \geq 1 .
$$

Combining (11) and (13) yields

$$
\frac{\lambda_{t+1}^{*}}{\lambda_{t}^{*}}=\frac{q_{t+1}}{q_{t}} \frac{\lambda_{t+1}}{\lambda_{t}}
$$

This condition determines the relation between the levels of domestic and foreign marginal utility and the real exchange rate up to a constant $\xi$ (which depends on initial endowments):

$$
\lambda_{t}^{*}=\xi q_{t} \lambda_{t}
$$

\section{$2.4 \quad$ Log-linearized equilibrium}

For the empirical implementation we employ a log-linear approximation to the model's equilibrium conditions around the non-stochastic steady state. The latter is described in Appendix B. Thus, define the $\log$ deviation of a variable $x_{t}$ from its steady state $x$ as $\hat{x}_{t} \equiv \log \left(x_{t} / x\right) \approx\left(x_{t}-x\right) / x$, such that $100 \times \hat{x}_{t}$ is approximately the percentage deviation of $x_{t}$ from $x$. Furthermore, we denote as $\tilde{x}_{t}=x \hat{x}_{t}$ the absolute deviation of $x_{t}$ from $x$. Using these relations, the following log-linearized system of equilibrium equations is derived in Appendix $\mathrm{C} 8$

\section{Domestic households.}

$$
\begin{aligned}
\hat{\lambda}_{t} & =\varepsilon_{c, t}-\sigma \hat{c}_{t} \\
\eta \hat{n}_{t} & =\hat{\lambda}_{t}+\hat{w}_{t}
\end{aligned}
$$

\footnotetext{
${ }^{8}$ Variables with bars denote steady state values which we take as given.
} 
Foreign households.

$$
\hat{\lambda}_{t}^{*}=-\sigma \hat{c}_{t}^{*}
$$

\section{Production and pricing.}

$$
\begin{aligned}
\hat{y}_{H, t} & =\hat{a}_{t}+\hat{n}_{t} \\
\widehat{m c}_{t} & =\frac{\vartheta}{1-\vartheta} \hat{q}_{t}+\hat{w}_{t}-\hat{a}_{t} \\
\hat{\pi}_{H, t} & =\frac{(1-\phi)(1-\phi \beta)}{\phi} \widehat{m c}_{t}+\beta E_{t} \hat{\pi}_{H, t+1} \\
\hat{\pi}_{t} & =\hat{\pi}_{H, t}+\frac{\vartheta}{1-\vartheta}\left(\hat{q}_{t}-\hat{q}_{t-1}\right)
\end{aligned}
$$

\section{Capital market.}

$$
\begin{aligned}
\hat{\lambda}_{t}^{*} & =\hat{q}_{t}+\hat{\lambda}_{t} \\
\hat{\lambda}_{t} & =E_{t} \hat{\lambda}_{t+1}+R_{H, t}-E_{t} \hat{\pi}_{t+1}-\frac{1}{1-\bar{\delta}} E_{t} \tilde{\delta}_{t+1} \\
\hat{\lambda}_{t}^{*} & =E_{t} \hat{\lambda}_{t+1}^{*}+\hat{R}_{F, t}-E_{t} \hat{\pi}_{t+1}^{*}-\frac{1}{1-\bar{\delta}} E_{t} \tilde{\delta}_{t+1} \\
E_{t} \tilde{\delta}_{t+1} & =\Phi(1-\bar{\delta})(1+\bar{f}) E_{t} \hat{b}_{t+1}
\end{aligned}
$$

\section{Policy.}

$$
\begin{aligned}
\hat{q}_{t}+\hat{b}_{F, t}-\hat{R}_{F, t} & =\hat{f}_{t}+\hat{b}_{H, t}-\hat{R}_{H, t} \\
(1+\bar{f}) \hat{b}_{t}= & \hat{b}_{H, t-1}-\hat{\pi}_{t}+\bar{f}\left(\hat{q}_{t}+\hat{b}_{F, t-1}-\hat{\pi}_{t}^{*}\right) \\
\hat{b}_{H, t}-\hat{R}_{H, t}+\bar{f}\left(\hat{q}_{t}+\hat{b}_{F, t}-\hat{R}_{F, t}\right)= & \frac{(1-\kappa)(1+\bar{f})}{\beta(1-\bar{\delta})} \hat{b}_{t}-\varepsilon_{\tau, t} \\
& +\frac{\kappa+\beta(1-\bar{\delta})-1}{\beta(1-\bar{\delta})(1+\bar{f})^{-1}}\left(\hat{g}_{t}-\frac{\vartheta}{1-\vartheta} \hat{q}_{t}\right) \\
\hat{R}_{H, t}= & \alpha_{\pi} \hat{\pi}_{t}+\varepsilon_{R, t}
\end{aligned}
$$

Market clearing.

$$
\begin{aligned}
\hat{y}_{H, t}= & (1-\vartheta) \bar{s}_{c} \hat{c}_{t}+\left[1-(1-\vartheta) \bar{s}_{c}-\bar{s}_{g}\right] \hat{c}_{t}^{*} \\
& +\left(\vartheta \bar{s}_{c}+\frac{1-(1-\vartheta) \bar{s}_{c}-\bar{s}_{g}}{1-\vartheta}\right) \hat{q}_{t}+\bar{s}_{g} \hat{g}_{t}
\end{aligned}
$$




\section{Stochastic processes.}

$$
\begin{aligned}
\hat{a}_{t}= & \rho_{a} \hat{a}_{t-1}+\varepsilon_{a, t} \\
\hat{g}_{t}= & \rho_{g} \hat{g}_{t-1}+\varepsilon_{g, t} \\
\hat{f}_{t}= & \rho_{f} \hat{f}_{t-1}+\varepsilon_{f, t} \\
\rho_{0 *}^{c c} \hat{c}_{t}^{*}= & \rho_{1 *}^{c c} \hat{c}_{t-1}^{*}+\rho_{1 *}^{c \pi} \hat{\pi}_{t-1}^{*}+\rho_{2 *}^{c c} \hat{c}_{t-2}^{*}+\rho_{2 *}^{c \pi} \hat{\pi}_{t-2}^{*} \\
& +\rho_{3 *}^{c c} \hat{c}_{t-3}^{*}+\rho_{3 *}^{c \pi} \hat{\pi}_{t-3}^{*}+\rho_{4 *}^{c c} \hat{c}_{t-4}^{*}+\rho_{4 *}^{c \pi} \hat{\pi}_{t-4}^{*}+\varepsilon_{c^{*}, t} \\
\rho_{0 *}^{\pi \pi} \hat{\pi}_{t}^{*}+\rho_{0 *}^{\pi c} \hat{c}_{t}^{*}= & \rho_{1 *}^{\pi \pi} \hat{\pi}_{t-1}^{*}+\rho_{1 *}^{\pi c} \hat{c}_{t-1}^{*}+\rho_{2 *}^{\pi \pi} \hat{\pi}_{t-2}^{*}+\rho_{2 *}^{\pi c} \hat{c}_{t-2}^{*} \\
& +\rho_{3 *}^{\pi \pi} \hat{\pi}_{t-3}^{*}+\rho_{3 *}^{\pi c} \hat{c}_{t-3}^{*}+\rho_{4 *}^{\pi \pi} \hat{\pi}_{t-4}^{*}+\rho_{4 *}^{\pi c} \hat{c}_{t-4}^{*}+\varepsilon_{\pi^{*}, t}
\end{aligned}
$$

We then have the following definition: A rational expectations equilibrium is a set of sequences $\left\{\hat{c}_{t}, \hat{c}_{t}^{*}, \hat{\lambda}_{t}, \hat{\lambda}_{t}^{*}, \hat{n}_{t}, \hat{w}_{t}, \hat{a}_{t}, \hat{y}_{H, t}, \widehat{m c}_{t}, \hat{q}_{t}, \hat{\pi}_{H, t}, \hat{\pi}_{t}, \hat{\pi}_{t}^{*}, \hat{b}_{t}, \hat{b}_{H, t}, \hat{b}_{F, t}, \hat{f}_{t}, \hat{g}_{t}, \hat{R}_{H, t}, \hat{R}_{F, t}, \tilde{\delta}_{t}\right\}_{t=0}^{\infty}$ satisfying (16)-(36) and the transversality conditions, for given initial asset endowments $B_{H,-1}$ and $B_{F,-1}$ and initial price levels $P_{H,-1}$ and $P_{F,-1}$. The i.i.d. innovations are $\left\{\varepsilon_{a, t}, \varepsilon_{c, t}, \varepsilon_{f, t}, \varepsilon_{g, t}\right.$, $\left.\varepsilon_{R, t}, \varepsilon_{\tau, t}, \varepsilon_{c^{*}, t}, \varepsilon_{\pi^{*}, t}\right\}_{t=0}^{\infty}$.

\section{Empirical Implementation}

The linearized model is estimated using Bayesian methods as described in An and Schorfheide (2007) 9 We apply full information estimation techniques since they provide a natural framework for formal model comparisons. To our knowledge, this is the first study which estimates a dynamic stochastic general equilibrium model for Turkey. As a consequence we hardly have access to prior information on the model's deep structural parameters. Therefore, we use uniform priors for those parameters as we would with restricted maximum likelihood estimation. However, the standard deviations of the shocks turned out to be weakly identified especially for the model without default risk, which may be a consequence of possible model misspecification. In order to avoid implausible estimates for those parameters, we elicit (diffuse) priors centered on values which we deem reasonable, as described below.

\subsection{Econometric methodology}

Formally, let $P\left(\theta_{M_{i}} \mid M_{i}\right)$ denote the prior distribution of the vector of structural parameters $\theta_{M_{i}}$ for model $M_{i}$, and let $L\left(Y^{T} \mid \theta_{M_{i}}, M_{i}\right)$ denote the likelihood function for the observed data $Y^{T}=Y_{1}, \ldots, Y_{T}$. Collect the model variables in the vector $x_{t}$, and let $\varepsilon_{t}$ and $\zeta_{t}$ denote the

\footnotetext{
${ }^{9}$ We use version 4.1.1 of the Dynare toolbox for MATLAB for the computations.
} 
vectors of structural shocks and expectational errors, respectively. The log-linearized model

$$
A x_{t}=B x_{t-1}+C \varepsilon_{t}+D \zeta_{t}
$$

is solved using standard perturbation techniques, which yields as solution the linear statespace representation

$$
\begin{aligned}
& x_{t}=F x_{t-1}+G \varepsilon_{t}, \quad \varepsilon_{t} \sim N I D\left(0, \Sigma_{\varepsilon}\right) \\
& Y_{t}=H x_{t}+u_{t}, \quad u_{t} \sim N I D\left(0, \Sigma_{u}\right)
\end{aligned}
$$

for $t=1, \ldots, T$. The first equation is the state transition equation and the second equation is the observation equation with measurement errors collected in $u_{t}$.

The Kalman filter is applied to evaluate the likelihood of the observables 10 The posterior distribution of the vector of parameters is obtained using Bayes' rule:

$$
P\left(\theta_{M_{i}} \mid Y^{T}, M_{i}\right)=\frac{L\left(Y^{T} \mid \theta_{M_{i}}, M_{i}\right) P\left(\theta_{M_{i}} \mid M_{i}\right)}{\int L\left(Y^{T} \mid \theta_{M_{i}}, M_{i}\right) P\left(\theta_{M_{i}} \mid M_{i}\right) d \theta_{M_{i}}} \propto L\left(Y^{T} \mid \theta_{M_{i}}, M_{i}\right) P\left(\theta_{M_{i}} \mid M_{i}\right) .
$$

In order to evaluate the posterior, the Random Walk Metropolis (RWM) algorithm is used. In short, this algorithm constructs a Gaussian approximation around the mode of the posterior kernel $L\left(Y^{T} \mid \theta_{M_{i}}, M_{i}\right) P\left(\theta_{M_{i}} \mid M_{i}\right)$ and uses a scaled version of the asymptotic covariance matrix as the covariance matrix for a proposal distribution 11 Using rejection sampling, the algorithm then generates a sequence of draws from the posterior that can be averaged to approximate posterior moments of interest, such as location measures and measures of dispersion 12

We assess the evidence of model $M_{i}$ over an alternative model $M_{j}$ using posterior odds

\footnotetext{
${ }^{10}$ Since $x_{t}$ is stationary, the Kalman filter is initialized with the unconditional distribution of $x_{t}$.

${ }^{11}$ The (log) posterior kernel is maximized using Chris Sim's version of the BFGS quasi-Newton algorithm, which uses a line search and randomly perturbs the search direction if it reaches regions of non-existence or non-uniqueness of a stable rational expectations solution.

${ }^{12}$ Let $\tilde{\Sigma}_{M_{i}}$ denote the negate inverse Hessian at the posterior mode $\tilde{\theta}_{M_{i}}$. A starting value $\theta_{M_{i}}^{(0)}$ is drawn from $N\left(\tilde{\theta}_{M_{i}}, c_{0} \tilde{\Sigma}_{M_{i}}\right)$. For $s=1, \ldots, S$, a candidate vector $\breve{\theta}_{M_{i}}$ is drawn from the proposal distribution $N\left(\theta_{M_{i}}^{(s)}, c \tilde{\Sigma}_{M_{i}}\right)$. The jump from $\theta_{M_{i}}^{(s-1)}$ is accepted $\left(\theta_{M_{i}}^{(s)}=\breve{\theta}_{M_{i}}\right)$ with probability $\min \left\{1, r\left(\theta_{M_{i}}^{(s-1)}, \breve{\theta} \mid Y^{T}\right)\right\}$ and rejected $\left(\theta_{M_{i}}^{(s)}=\theta_{M_{i}}^{(s-1)}\right)$ otherwise, where

$$
r\left(\theta_{M_{i}}^{(s-1)}, \breve{\theta} \mid Y^{T}\right)=\frac{L\left(Y^{T} \mid \breve{\theta}_{M_{i}}, M_{i}\right) P\left(\breve{\theta}_{M_{i}} \mid M_{i}\right)}{L\left(Y^{T} \mid \theta_{M_{i}}^{(s-1)}, M_{i}\right) P\left(\theta_{M_{i}}^{(s-1)} \mid M_{i}\right)}
$$

In practice, we use $S=500,000$ and drop the first 250,000 draws to let the Markov chain produced by the RWM algorithm converge. The scaling factor $c_{0}$ is set to $2 c$, and we produce five chains with different starting values in order to assess convergence based on the diagnostics suggested by Brooks and Gelman's (1998). The scaling factor $c$ is set in order to achieve an average acceptance rate per chain of approximately $25 \%$.
} 
comparison. The ratio of the posterior probabilities of the two models is

$$
\frac{P\left(M_{i} \mid Y^{T}\right)}{P\left(M_{j} \mid Y^{T}\right)}=\frac{P\left(M_{i}\right)}{P\left(M_{j}\right)} \frac{p\left(Y^{T} \mid M_{i}\right)}{p\left(Y^{T} \mid M_{j}\right)}
$$

The first term on the right-hand side is the prior odds ratio in favor of model $M_{i}$. The second term is the Bayes factor summarizing the sample evidence in favor of model $M_{i}$. Here, the marginal data density $p\left(Y^{T} \mid M_{i}\right) \equiv \int L\left(Y^{T} \mid \theta_{M_{i}}, M_{i}\right) P\left(\theta_{M_{i}} \mid M_{i}\right) d \theta_{M_{i}}$ indicates the likelihood of model $M_{i}$ conditional on the observed data, and similarly for model $M_{j} 13$ Throughout the analysis, we set the prior odds ratio to 1.

Finally, for $t=1, \ldots, T$ the smoothed structural shocks $\varepsilon_{t \mid T}$ which, according to the model, have generated the observed data are recovered by an application of the Kalman filter at the posterior mean estimates of the model parameters. This step also yields smoothed estimates $x_{t \mid T}$ of the (unobserved) model variables. In order to evaluate the forecasting performance of alternative models, one-step ahead forecasts are computed as the estimates of the observed variables conditional on period $t$ information: $Y_{t+1 \mid t}=H x_{t+1 \mid t}$, where $x_{t+1 \mid t}$ is computed as $x_{t+1 \mid t}=F x_{t \mid t}$ and $x_{t \mid t}$ denotes the updated variables obtained from the application of the Kalman filter.

\subsection{Data description}

We use quarterly data on real Turkish output $\left(\mathrm{GDP}_{t}\right)$, real private consumption $\left(\mathrm{CONS}_{t}\right)$, the annual consumer price inflation rate $\left(\mathrm{INF}_{t}\right)$, the nominal interest rate on 3-month Turkish lira denominated treasury bills $\left(\mathrm{INT}_{t}\right)$, the real effective exchange rate $\left(\mathrm{REER}_{t}\right)$, real government consumption $\left(\mathrm{GOV}_{t}\right)$, real Turkish lira denominated domestic government debt $\left(\mathrm{DEBT}_{t}\right)$, real foreign consumption $\left(\mathrm{CONS}_{t}^{*}\right)$ and the foreign consumer price inflation rate $\left(\mathrm{INF}_{t}^{*}\right)$. The variables of the foreign economy $\left(\mathrm{CONS}_{t}^{*}\right.$ and $\left.\mathrm{INF}_{t}^{*}\right)$ are computed as a trade-weighted average of the U.S. and the Euro area, which are Turkey's main trading partners 14

The sample period is 1994:3-2008:2 ( $T=56$ observations). The starting point is chosen to reduce the impact of high inflation during the crisis period in the first two quarters of 1994 . In these quarters, annual inflation rates reached values up to 150 percent but they returned to about 60 percent in the third quarter of 1994 . The annual interest rate was almost 300 percent in 1994:2 but it returned to around 122 percent in 1994:3. Although such high

\footnotetext{
${ }^{13}$ The marginal data density is estimated using Geweke's (1999) modified harmonic mean estimator.

${ }^{14}$ We include domestic currency denominated debt as an observed variable since Turkey issues external (U.S. dollar and Euro denominated) debt only at maturities longer than 3 months. In addition, the observed nominal interest rate also refers to domestic currency denominated debt.
} 
inflation and interest rates could potentially be explained by large shocks, it seems unlikely that our assumptions on the statistical properties of the stochastic processes such as their $\mathrm{AR}(1)$ structure and normality of the disturbances, which we make to simplify econometric inference, are adequate to describe such crisis episodes.

Nominal variables are demeaned consistent with their steady state values. Real variables are in natural logarithms and they are detrended using a linear trend, since our model does not explicitly consider growth 15 Details on data definitions and the construction of the foreign variables are provided in Appendix $\mathrm{A}$. Domestic and foreign inflation $\left(\mathrm{INF}_{t}\right.$ and $\left.\mathrm{INF}_{t}^{*}\right)$ and the domestic interest rate $\left(\mathrm{INT}_{t}\right)$ are related to the model variables through the measurement equations

$$
\begin{aligned}
\mathrm{INF}_{t} & =4 \bar{\pi} \hat{\pi}_{t} \\
\mathrm{INF}_{t}^{*} & =4 \bar{\pi}^{*} \hat{\pi}_{t}^{*} \\
\mathrm{INT}_{t} & =4 \bar{R}_{H} \hat{R}_{H, t} .
\end{aligned}
$$

Furthermore, since the available data for the real effective exchange rate $\mathrm{REER}_{t}$ is constructed as a trade-weighted average of all trading partners of Turkey it is not exactly equivalent to the model-implied real exchange rate, given that we construct the foreign variables $\mathrm{CONS}_{t}^{*}$ and $\mathrm{INF}_{t}^{*}$ as a trade-weighted average of the U.S. and the Euro area. Thus, we include an error in the measurement equation for the real exchange rate:

$$
\operatorname{REER}_{t}=\hat{q}_{t}+u_{q, t}
$$

where $u_{q, t} \sim N I D\left(0, \sigma_{q}^{2}\right)$. The remaining observed variables are equal to the model variables, i.e. $\mathrm{GDP}_{t}=\hat{y}_{H, t}, \mathrm{CONS}_{t}=\hat{c}_{t}, \mathrm{GOV}_{t}=\hat{g}_{t}, \mathrm{DEBT}_{t}=\hat{b}_{H, t}$ and $\mathrm{CONS}_{t}^{*}=\hat{c}_{t}^{*}$. All observed variables are shown in Figure 1,

\subsection{Calibrated parameters}

The steady state values are calibrated consistent with sample averages. The average annual Turkish inflation rate over the period 1994:3-2008:2 was 37.2 percent. In order to match this value, we set the quarterly steady state inflation rate to $\pi=\bar{\pi}=1.093$. The average annualized 3-month treasury bill rate was approximately 72.4 percent, so we set the quarterly steady

\footnotetext{
${ }^{15}$ We have verified that our results are robust to the use of alternative trends, such as linear-quadratic or Hodrick-Prescott filtered trends, by estimating the basic and the augmented model on the alternatively detrended data. The estimates of the model's deep structural parameters are similar to the ones obtained with a linear trend, while the estimated shock variances tend to decrease.
} 

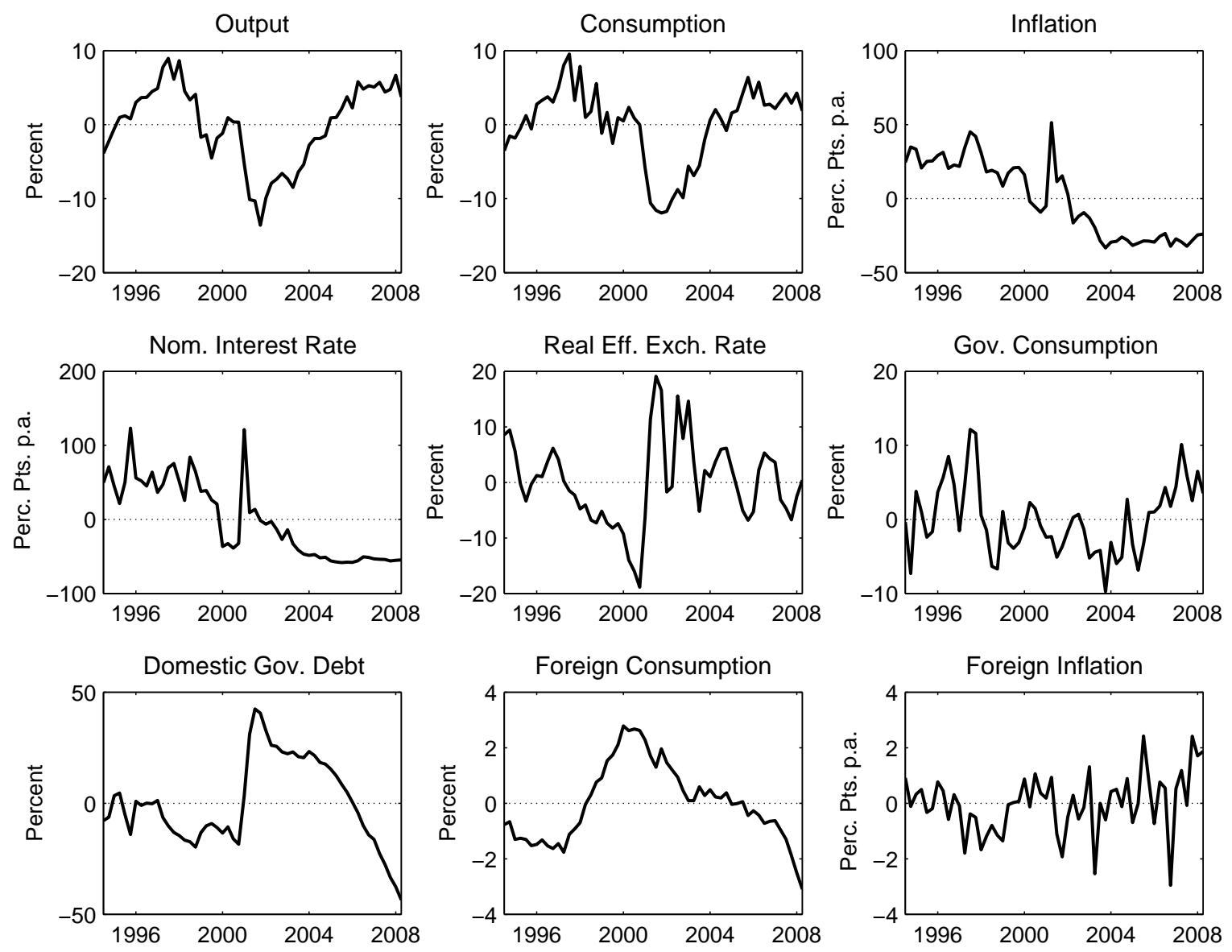

Figure 1: Data used in the estimation. Notes. Quarterly data, 1994:3-2008:2; real variables are measured in percentage deviations from a linear trend, nominal variables are demeaned and in annualized percentage terms.

state interest rate to $R_{H}=\bar{R}_{H}=1.181$. Further, we set the shares of private and government consumption in GDP $s_{c}$ and $s_{g}$, respectively, to their empirical counterparts. That is, $s_{c}=\bar{s}_{c}=0.683$ and $s_{g}=\bar{s}_{g}=0.108$. The steady state share of foreign currency denominated debt over domestic currency denominated debt is also set to its empirical counterpart, i.e. $f=\bar{f}=0.829$.

The parameters of the stochastic process for the foreign variables are calibrated by fitting an identified VAR(4) process to detrended (log) real foreign consumption and the demeaned annual foreign inflation rate:

$$
\begin{aligned}
{\left[\begin{array}{c}
\log c_{t}^{*} \\
\log \pi_{t}^{*}
\end{array}\right]=} & \left(I-\Phi_{1 *}-\Phi_{2 *}-\Phi_{3 *}-\Phi_{4 *}\right)\left[\begin{array}{c}
\log \bar{c}^{*} \\
\log \bar{\pi}^{*}
\end{array}\right]+\Phi_{1 *}\left[\begin{array}{c}
\log c_{t-1}^{*} \\
\log \pi_{t-1}^{*}
\end{array}\right] \\
& +\Phi_{2 *}\left[\begin{array}{c}
\log c_{t-2}^{*} \\
\log \pi_{t-2}^{*}
\end{array}\right]+\Phi_{3 *}\left[\begin{array}{c}
\log c_{t-3}^{*} \\
\log \pi_{t-3}^{*}
\end{array}\right]+\Phi_{4 *}\left[\begin{array}{c}
\log c_{t-4}^{*} \\
\log \pi_{t-4}^{*}
\end{array}\right]+\left[\begin{array}{c}
v_{c^{*}, t} \\
v_{\pi^{*}, t}
\end{array}\right],
\end{aligned}
$$


where $\left[v_{c^{*}, t}, v_{\pi^{*}, t}\right]^{\prime} \sim \operatorname{NID}\left(0, \Sigma_{*}\right)$. Our identifying assumption is that foreign consumption affects foreign inflation within a quarter but not vice versa. We apply a recursive Cholesky identification scheme: $\Sigma_{*}=C_{*} C_{*}^{\prime}$, where $C_{*}$ is a non-singular lower triangular matrix, which yields the structural shocks $\left[\varepsilon_{c^{*}, t}, \varepsilon_{\pi^{*}, t}\right]^{\prime} \sim N I D(0, I)$ as a linear combination of the reducedform innovations, i.e. $\left[\varepsilon_{c^{*}, t}, \varepsilon_{\pi^{*}, t}\right]^{\prime}=C_{*}^{-1}\left[v_{c^{*}, t}, v_{\pi^{*}, t}\right]^{\prime}$.

We calibrate steady state foreign inflation $\pi^{*}=\bar{\pi}^{*}$ to match an average quarterly foreign inflation rate of 0.6 percent over the period 1994:3-2008:2, or an average annual inflation rate of 2.4 percent. Foreign consumption and inflation are then included in the actual estimation step (calibrating the VAR parameters) in order to recover the shocks of foreign origin.

We also calibrate a small number of additional parameters that are inherently difficult to identify. This concerns the inverse of the Frisch elasticity of labor supply $\eta$ which we set to 2 , implying a labor supply elasticity of $1 / 2$ in line with the range of available estimates (see Christoffel, Coenen, and Warne, 2008). The subjective discount factor $\beta$ is set to 0.99, which implies a steady state default probability $\delta=\bar{\delta}=1-\bar{\pi} / \bar{R}_{H} / \beta=0.065$, in accordance with the average EMBIG spread on Turkish governments bonds over the sample period 16 Furthermore, the foreign degree of openness towards the domestic economy $\vartheta^{*}$ is set to 0.004 , which is approximately equal to the weighted average, according to the trade weights used to construct foreign variables, of the shares of imports from Turkey in GDP of the Euro area and the U.S.17

\subsection{Prior distributions}

Our priors are summarized in Table1. The prior distributions are assumed to be independent across parameters. We elicit uniform priors, restricted to theoretically plausible ranges, on all deep structural parameters. In particular, the inverse elasticity of intertemporal substitution $\sigma$ and the inflation feedback in the Taylor rule $\alpha_{\pi}$ obtain a lower bound of 0 and upper bounds

\footnotetext{
${ }^{16}$ In Section 4.3 we check the sensitivity of our results to alternative values for $\beta$.

${ }^{17}$ This weighted average is calculated as follows, taking as reference year the year 2007 due to data availability. The main Turkish exports markets in 2007 were the European Union (56.4\%), Russia (4.4\%), the U.S. (3.9\%), Romania (3.4\%), the United Arab Emirates (3.0\%) and Iraq (2.6\%) (see http://ec.europa.eu/trade/creating-opportunities/bilateral-relations/countries/turkey). The total goods exports volume of Turkey was approximately 107.2 billion U.S. dollars in 2007 (see the country statistical profile for Turkey on http://stats.oecd.org). Total nominal U.S. private consumption in 2007 was $39,752.5$ billion U.S. dollars, such that the share of imports from Turkey in U.S. private consumption can be calculated as $\vartheta^{U S}=\frac{0.039 \times 107.2}{39752.5} \simeq 0.000105=0.0105 \%$. Similarly, total nominal Euro area private consumption in 2007 was 5,058.8 billion Euros, or 6,922.7 billion U.S. dollars given an average Euro per U.S. dollar nominal exchange rate of 0.731 in 2007. The share of imports from Turkey in Euro area private consumption can thus be calculated as $\vartheta^{E A}=\frac{0.564 \times 107.2}{6922.7} \simeq 0.008734=0.8734 \%$. Hence, we obtain the foreign degree of openness towards the domestic economy as $\vartheta^{*}=\frac{\mu^{E A} \vartheta^{E A}+\mu^{U S}{ }_{\vartheta} U S}{\mu^{E A}+\mu^{U S}} \simeq 0.003858$, where the weights are $\mu^{E A}=0.77$ and $\mu^{U S}=1$ (see Appendix A).
} 
of 20 and 10, respectively. The Calvo probability $\phi$ and the domestic degree of openness $\vartheta$ are restricted to the range $[0,1]$, consistent with their theoretically feasible values. In order to ensure a positive default elasticity, which is the case if steady state domestic debt is positive, the debt response $\kappa$ in the fiscal policy rule is restricted to be larger than $1-\beta(1-\bar{\delta})$, and we impose an upper bound of 1018

We also use uniform priors on the range $[0,1]$ for the $\operatorname{AR}(1)$ coefficients of the stochastic processes. However, as discussed above, in order to rule out implausible estimates for the standard deviations of the innovation components for any version of the model, we impose tighter priors on those parameters. That is, we elicit inverse gamma priors with mean 0.05 and an infinite standard deviation, implying that a larger portion of the probability mass tends to fall on existing estimates for small open economies (see e.g. Adolfson, Laséen, Lindé, and Villani, 2007; Lubik and Schorfheide, 2007; Justiniano and Preston, 2008) while still covering all of the theoretically feasible range.

\section{Estimation Results}

We organize the discussion of results as follows. Section 4.1 compares the basic model without perceived default risk and the augmented model in terms of parameter estimates, posterior odds comparisons, model-implied shocks, business cycle moments, forecasting performance, and variance decompositions. Section 4.2 implements several counterfactual experiments based on the estimated model, in order to understand the role of perceived default risk and to assess policy implications and presents estimated impulse responses. Robustness checks are deferred to Section 4.3

\subsection{Model comparison: Basic vs. augmented model}

\subsubsection{Parameter estimates and marginal data densities}

The estimation results for both the basic and the augmented model are summarized in Table 1. The table reports the posterior means of the estimated parameters, their $90 \%$ probability intervals and the $(\log )$ marginal data densities associated with the two models. Several results stand out. The estimated deep structural parameters, inverse intertemporal substitution elasticity $\sigma$, price stickiness $\phi$ and degree of openness $\vartheta$, are broadly in line with existing estimates for small open economies (see, for example Lubik and Schorfheide, 2007; Justiniano

\footnotetext{
${ }^{18}$ Note that $\frac{b_{H}}{\pi}=\frac{g(1+\bar{f})^{-1}}{\kappa+\beta(1-\delta)-1}$ as shown in Appendix $\left[\right.$ and therefore $\Phi>0$ when $\frac{b_{H}}{\pi}>0$, which is the case if $\kappa>1-\beta(1-\bar{\delta})$ since $g, \bar{f}>0$.
} 
Table 1: Prior distributions and posterior estimates. ${ }^{\mathrm{a}}$

\begin{tabular}{|c|c|c|c|c|c|c|c|}
\hline \multirow[b]{2}{*}{ Parameter } & \multirow[b]{2}{*}{ Definition } & \multirow[b]{2}{*}{ Domain } & \multirow[b]{2}{*}{ Prior $^{b}$} & \multicolumn{2}{|c|}{ With sovereign risk $\left(M_{1}\right)$} & \multicolumn{2}{|c|}{ No sovereign risk $\left(M_{2}\right)$} \\
\hline & & & & Post. mean & $90 \%$ int. & Post. mean & $90 \%$ int. \\
\hline$\sigma$ & Inv. elast. of intertemp. subst. & $\mathbb{R}^{+}$ & $\mathrm{U}(0,20)$ & 0.59 & {$[0.44,0.75]$} & 15.85 & {$[13.82,17.84]$} \\
\hline$\phi$ & Calvo price stickiness & {$[0,1]$} & $\mathrm{U}(0,1)$ & 0.19 & {$[0.00,0.33]$} & 0.72 & {$[0.67,0.78]$} \\
\hline$\vartheta$ & Degree of openness & {$[0,1]$} & $\mathrm{U}(0,1)$ & 0.42 & {$[0.29,0.54]$} & 0.03 & {$[0.00,0.05]$} \\
\hline$\alpha_{\pi}$ & Taylor rule inflation response & $\mathbb{R}$ & $\mathrm{U}(0,10)$ & 2.10 & {$[1.81,2.40]$} & 1.25 & {$[1.16,1.33]$} \\
\hline$\kappa$ & Tax rule debt response & $\mathbb{R}$ & $\mathrm{U}\left(\kappa_{L}, 10\right)^{\mathrm{c}}$ & 0.53 & {$[0.46,0.60]$} & 0.10 & {$[0.08,0.11]$} \\
\hline$\Phi$ & Default elasticity & $\mathbb{R}^{+}$ & $\mathrm{U}(0,10)$ & 0.25 & {$[0.21,0.28]$} & - & - \\
\hline$\rho_{a}$ & $\mathrm{AR}(1)$ technology & {$[0,1)$} & $\mathrm{U}(0,1)$ & 0.91 & {$[0.84,0.99]$} & 0.64 & {$[0.54,0.74]$} \\
\hline$\rho_{g}$ & $\mathrm{AR}(1)$ gov. consumption & {$[0,1)$} & $\mathrm{U}(0,1)$ & 0.50 & {$[0.32,0.67]$} & 0.79 & {$[0.71,0.88]$} \\
\hline$\rho_{f}$ & $\mathrm{AR}(1)$ foreign debt ratio & {$[0,1)$} & $\mathrm{U}(0,1)$ & 0.86 & {$[0.77,0.96]$} & 0.66 & {$[0.24,1.00]$} \\
\hline$\sigma_{a}$ & Std. dev. technology shocks & $\mathbb{R}^{+}$ & $\operatorname{IG}(0.05, \infty)$ & 0.02 & {$[0.02,0.03]$} & 0.06 & {$[0.03,0.08]$} \\
\hline$\sigma_{g}$ & Std. dev. gov. consumption shocks & $\mathbb{R}^{+}$ & $\mathrm{IG}(0.05, \infty)$ & 0.04 & {$[0.03,0.05]$} & 0.23 & {$[0.18,0.27]$} \\
\hline$\sigma_{f}$ & Std. dev. foreign debt ratio shocks & $\mathbb{R}^{+}$ & $\operatorname{IG}(0.05, \infty)$ & 0.31 & {$[0.26,0.36]$} & 0.04 & {$[0.01,0.09]$} \\
\hline$\sigma_{\tau}$ & Std. dev. fiscal policy shocks & $\mathbb{R}^{+}$ & $\mathrm{IG}(0.05, \infty)$ & 0.10 & {$[0.08,0.13]$} & 0.12 & {$[0.09,0.16]$} \\
\hline$\sigma_{R}$ & Std. dev. interest rate shocks & $\mathbb{R}^{+}$ & $\mathrm{IG}(0.05, \infty)$ & 0.07 & {$[0.06,0.08]$} & 0.06 & {$[0.05,0.07]$} \\
\hline$\sigma_{c}$ & Std. dev. demand shocks & $\mathbb{R}^{+}$ & $\operatorname{IG}(0.05, \infty)$ & 0.02 & {$[0.01,0.02]$} & 0.83 & {$[0.67,0.99]$} \\
\hline$\sigma_{q}$ & Std. dev. meas. error on REER ${ }_{t}$ & $\mathbb{R}^{+}$ & $\operatorname{IG}(0.05, \infty)$ & 0.09 & {$[0.08,0.10]$} & 0.21 & {$[0.17,0.25]$} \\
\hline $\log p\left(Y^{T} \mid M_{i}\right)$ & Log marginal data density ${ }^{\mathrm{d}}$ & & & 873.67 & & 704.64 & \\
\hline
\end{tabular}

a The estimation results are based on 500,000 accepted draws from the RWM sampler, dropping the first 250,000 draws.

${ }^{\mathrm{b}} \mathrm{U}(a, b)$ refers to the continuous uniform distribution with lower bound $a$ and upper bound $b$; $\operatorname{IG}(c, d)$ refers to the inverse gamma distribution with mean $c$ and std. deviation $d$.

c The lower bound is $\kappa_{L}=1-\beta(1-\bar{\delta})$, which ensures that steady state domestic debt $b_{H} / \pi$ is positive such that $\Phi>0$ (see Appendix C).

d The marginal data density is estimated using Geweke's (1999) modified harmonic mean estimator. 
and Preston, 2008) but, most notably, the model without sovereign risk implies a significantly higher $\sigma$. We provide an interpretation of this result below.

The estimated default elasticity $\Phi$ in the model with sovereign risk is 0.25 , such that the expected default rate is highly debt-elastic. This result confirms the findings in Budina and van Wijnbergen (2008) who show that higher debt service obligations lead to stronger expectations that these debt obligations might not be met. Furthermore, both the Taylor rule inflation response $\alpha_{\pi}$ and the tax feedback $\kappa$ are larger in the model with sovereign risk but in line with existing estimates (see Yazgan and Yilmazkuday, 2007). All three policy parameters are well identified. The fact that a positive default elasticity implies a relatively high tax feedback is not surprising, since this is required - by prior assumption - in order to prevent the unstable equilibrium dynamics suggested by Blanchard (2005) and analyzed in Schabert and van Wijnbergen (2010).

Third, the standard deviations of the structural innovations are significantly larger in the basic model, whereas the model with sovereign risk requires much smaller shocks in order to describe the data. An exception is the standard deviation of the foreign debt share, which is however not well identified in the model without sovereign risk. The remaining standard deviations are also better identified in the model with sovereign risk. A formal model comparison based on the marginal data density clearly supports the model with sovereign risk. The Bayes factor in favor of this model $\left(M_{1}\right)$ over the model without sovereign risk $\left(M_{2}\right)$ is

$$
\frac{p\left(Y^{T} \mid M_{1}\right)}{p\left(Y^{T} \mid M_{2}\right)}=\frac{\exp (873.67)}{\exp (704.64)} \approx 2.6 \times 10^{73}
$$

indicating strong support for the model with sovereign risk, conditional on the observed data.

\subsubsection{Estimated default rate and EMBIG spreads}

How do the size and dynamics of the estimated expected default rate compare to existing estimates of sovereign risk in Turkey? Figure 2 plots the expected default rate $E_{t} \tilde{\delta}_{t+1}$, as implied by the Kalman smoother at the posterior mean, against the J.P. Morgan Emerging Market Bond Index Global (EMBIG) spreads on (i) Turkish bonds denominated in U.S. dollar over U.S. treasury bonds and (ii) Euro denominated Turkish bonds over German bunds 19 In general there is a strong co-movement, although the EMBIG indicates somewhat smaller default rates before and during the 2000-2001 crisis and larger rates thereafter. The

\footnotetext{
${ }^{19}$ All variables are reported in basis points, and the steady state value $\bar{\delta}$ is added to the estimated default rate in absolute deviations from steady state, $E_{t} \tilde{\delta}_{t+1}$, in order to obtain the actual estimated default rate $E_{t} \delta_{t+1}$.
} 


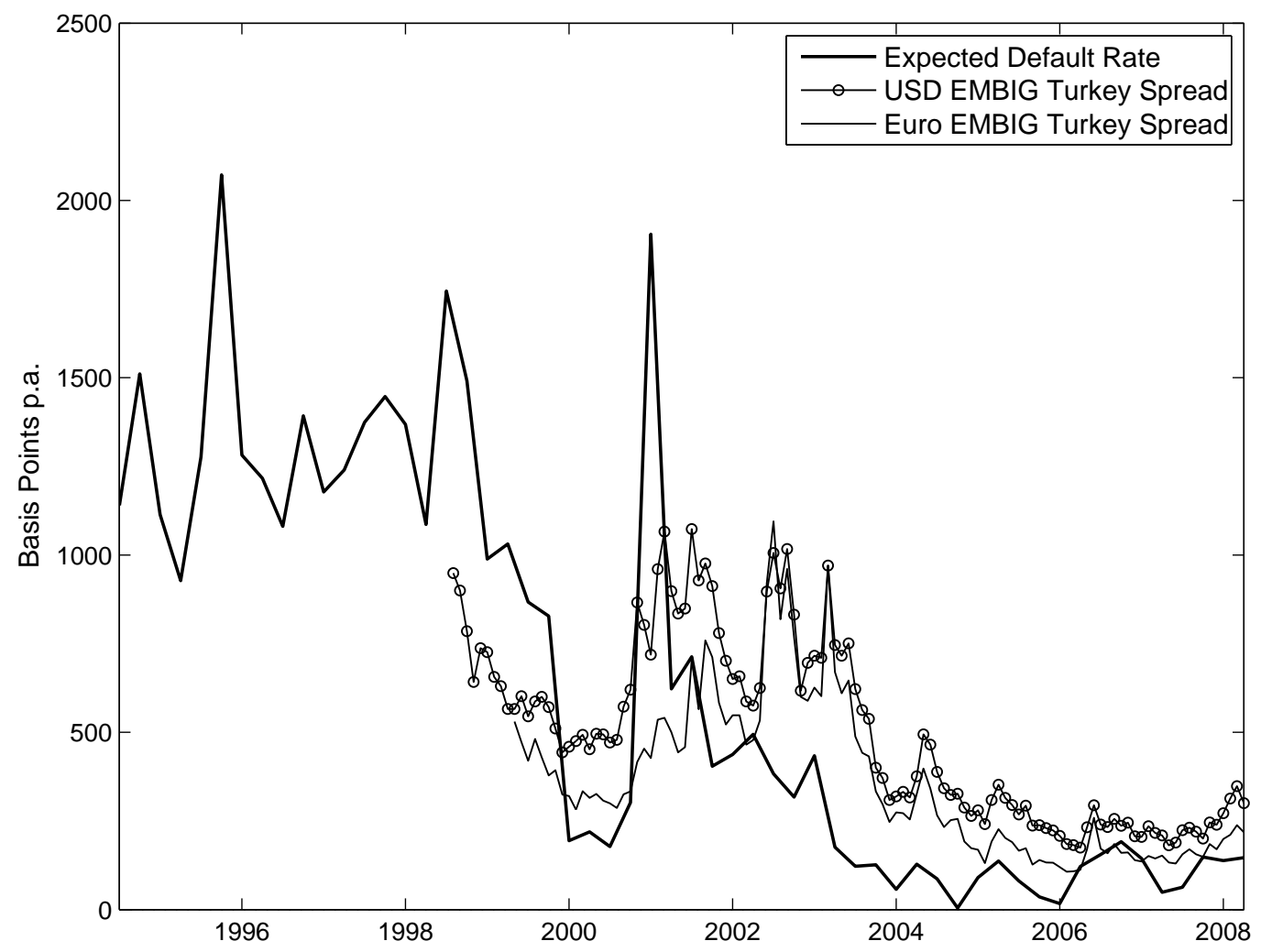

Figure 2: Estimated expected default rate $\left(E_{t} \tilde{\delta}_{t+1}\right)$ and J.P. Morgan EMBIG Turkey spreads. Notes. The default rate is the estimate implied by the Kalman smoother at the posterior mean (1994:3-2008:2); source of EMBIG spreads (monthly data): J.P. Morgan and Bloomberg; 'USD' indicates spreads on U.S. dollar Brady bonds and loans over U.S. treasury bonds (08/1998-06/2008); 'Euro' indicates spreads on euro denominated bonds and loans over German bunds (05/1999-06/2008).

correlations between the model-implied expected default rate and (i) and (ii) are 0.66 and 0.56 , respectively. Given the degree of abstraction of the theoretical model, based on this evidence one may nevertheless conclude that it provides a realistic description of sovereign risk in Turkey.

\subsubsection{Business cycle moments}

In order to provide a first intuition on the factors underlying the support for the model with sovereign risk, we discuss the business cycle implications of the two estimated models in terms of selected moments. Table 2 compares the standard deviations, correlations with output and autocorrelations of the observed data with the corresponding model-implied moments. These moments are computed at the posterior mean conditional on all structural shocks. The results show that the basic model overpredicts the volatility of domestic output, the real exchange rate and the fiscal variables but significantly underpredicts the volatility of inflation (by a 
factor of 26) and the nominal interest rate. The model with sovereign risk comes closer in terms of the volatility of output, the real exchange rate and also inflation. It overstates the latter, but only by a factor of 2.5. In sum, the augmented model tends to overpredict the variability of nominal variables and debt. We provide a discussion on this in Section 4.2 , When comparing the relative volatility of the components of output, the next two columns of Table 2 show that the augmented model also more closely matches the relative volatility of domestic private and government consumption relative to output.

Both versions of the model have trouble in matching the observed correlations with domestic output, but it stands out that the cyclicality of domestic consumption is significantly understated by the basic model whereas the augmented model implies a perfect match. Also in terms of autocorrelation patterns, the model with sovereign risk implies a better fit although there are some exceptions such as the real exchange rate. Most notably, however, the autocorrelations of domestic output and consumption are matched significantly more closely by the augmented model. Overall, we conclude that the proposed modification of the basic model leads to a better description of the observed data in terms of business cycle facts.

\subsubsection{Model-implied shocks}

Next, in order to illustrate the differences in terms of the size of shocks required to fit the data, Figure 3 shows the estimated structural innovations implied by the Kalman smoother at the posterior mean according to both model versions. The model without sovereign risk generates much larger domestic demand shocks and government consumption shocks, and also larger technology shocks and measurement errors on the real exchange rate. Overall, the model with sovereign risk requires significantly smaller shocks. An exception is the foreign debt ratio. Importantly, the estimated innovations from the model without sovereign risk can hardly be defended to satisfy the properties of the assumed underlying stochastic processes, i.e. no autocorrelation 20 The model with sovereign risk, on the other hand, comes closer to those assumptions except for occasional spikes during the financial crisis of 2000-2001.

\subsubsection{Forecasting performance}

Figure 4 compares the observed variables and their one-step ahead forecasts implied by the two estimated models. The one-step ahead forecasts are computed by applying the Kalman filter at the respective posterior mean estimates. From visual inspection, while both models

\footnotetext{
${ }^{20}$ In the augmented model the hypothesis of no autocorrelation cannot be rejected at the $1 \%$ level in case of two shocks while in the basic model it cannot be not rejected in case of five shocks.
} 
Table 2: Selected moments of observed data and model-implied moments. ${ }^{a}$

\begin{tabular}{|c|c|c|c|c|c|c|c|c|c|c|}
\hline & \multicolumn{2}{|c|}{$\begin{array}{l}\text { Standard } \\
\text { deviation }\end{array}$} & \multicolumn{2}{|c|}{$\begin{array}{l}\text { Std. deviation } \\
\text { rel. to output }\end{array}$} & \multicolumn{2}{|c|}{$\begin{array}{l}\text { Correlation } \\
\text { with output }\end{array}$} & \multicolumn{2}{|c|}{$\begin{array}{l}\text { Autocorrelation } \\
\text { of order } 1\end{array}$} & \multicolumn{2}{|c|}{$\begin{array}{c}\text { Autocorrelation } \\
\text { of order } 4\end{array}$} \\
\hline & Data & Model & Data & Model & Data & Model & Data & Model & Data & Model \\
\hline \multicolumn{11}{|c|}{ With sovereign risk } \\
\hline Output & 0.05 & 0.06 & 1.00 & 1.00 & 1.00 & 1.00 & 0.92 & 0.91 & 0.61 & 0.68 \\
\hline Consumption & 0.05 & 0.06 & 0.97 & 1.02 & 0.94 & 0.94 & 0.86 & 0.78 & 0.55 & 0.59 \\
\hline Inflation & 0.26 & 0.64 & - & - & 0.04 & -0.39 & 0.90 & 0.93 & 0.76 & 0.81 \\
\hline Interest rate & 0.52 & 1.42 & - & - & 0.05 & -0.40 & 0.79 & 0.96 & 0.71 & 0.84 \\
\hline Real exch. rate & 0.08 & 0.10 & - & - & -0.41 & 0.31 & 0.71 & 0.11 & -0.02 & 0.09 \\
\hline Gov. consumption & 0.05 & 0.05 & 0.89 & 0.80 & 0.58 & 0.03 & 0.60 & 0.50 & 0.23 & 0.06 \\
\hline Domestic debt & 0.19 & 0.57 & - & - & -0.76 & -0.33 & 0.94 & 0.94 & 0.58 & 0.77 \\
\hline For. consumption & 0.01 & 0.03 & 0.26 & 0.52 & -0.60 & 0.04 & 0.97 & 0.99 & 0.75 & 0.87 \\
\hline For. inflation & 0.01 & 0.01 & - & - & 0.11 & -0.39 & 0.17 & 0.26 & -0.06 & 0.03 \\
\hline Default rate & - & 0.15 & - & - & - & -0.35 & - & 0.96 & - & 0.84 \\
\hline \multicolumn{11}{|c|}{ No sovereign risk } \\
\hline Output & 0.05 & 0.08 & 1.00 & 1.00 & 1.00 & 1.00 & 0.92 & 0.76 & 0.61 & 0.60 \\
\hline Consumption & 0.05 & 0.05 & 0.97 & 0.65 & 0.94 & 0.26 & 0.86 & 0.04 & 0.55 & 0.03 \\
\hline Inflation & 0.26 & 0.01 & - & - & 0.04 & 0.63 & 0.90 & 0.83 & 0.76 & 0.57 \\
\hline Interest rate & 0.52 & 0.43 & - & - & 0.05 & 0.41 & 0.79 & 0.61 & 0.71 & 0.42 \\
\hline Real exch. rate & 0.08 & 0.38 & - & - & -0.41 & 0.65 & 0.71 & 0.66 & -0.02 & 0.57 \\
\hline Gov. consumption & 0.05 & 0.37 & 0.89 & 4.50 & 0.58 & 0.37 & 0.60 & 0.79 & 0.23 & 0.40 \\
\hline Domestic debt & 0.19 & 0.44 & - & - & -0.76 & 0.12 & 0.94 & 0.98 & 0.58 & 0.93 \\
\hline For. consumption & 0.01 & 0.03 & 0.26 & 0.35 & -0.60 & -0.77 & 0.97 & 0.99 & 0.75 & 0.87 \\
\hline For. inflation & 0.01 & 0.01 & - & - & 0.11 & 0.07 & 0.17 & 0.26 & -0.06 & 0.03 \\
\hline
\end{tabular}

a The model-implied moments are computed from the solution of the model at the posterior mean.

$\mathrm{b}$ The standard deviations of inflation and the interest rate are in annual terms, the remaining standard deviations are in quarterly terms. 

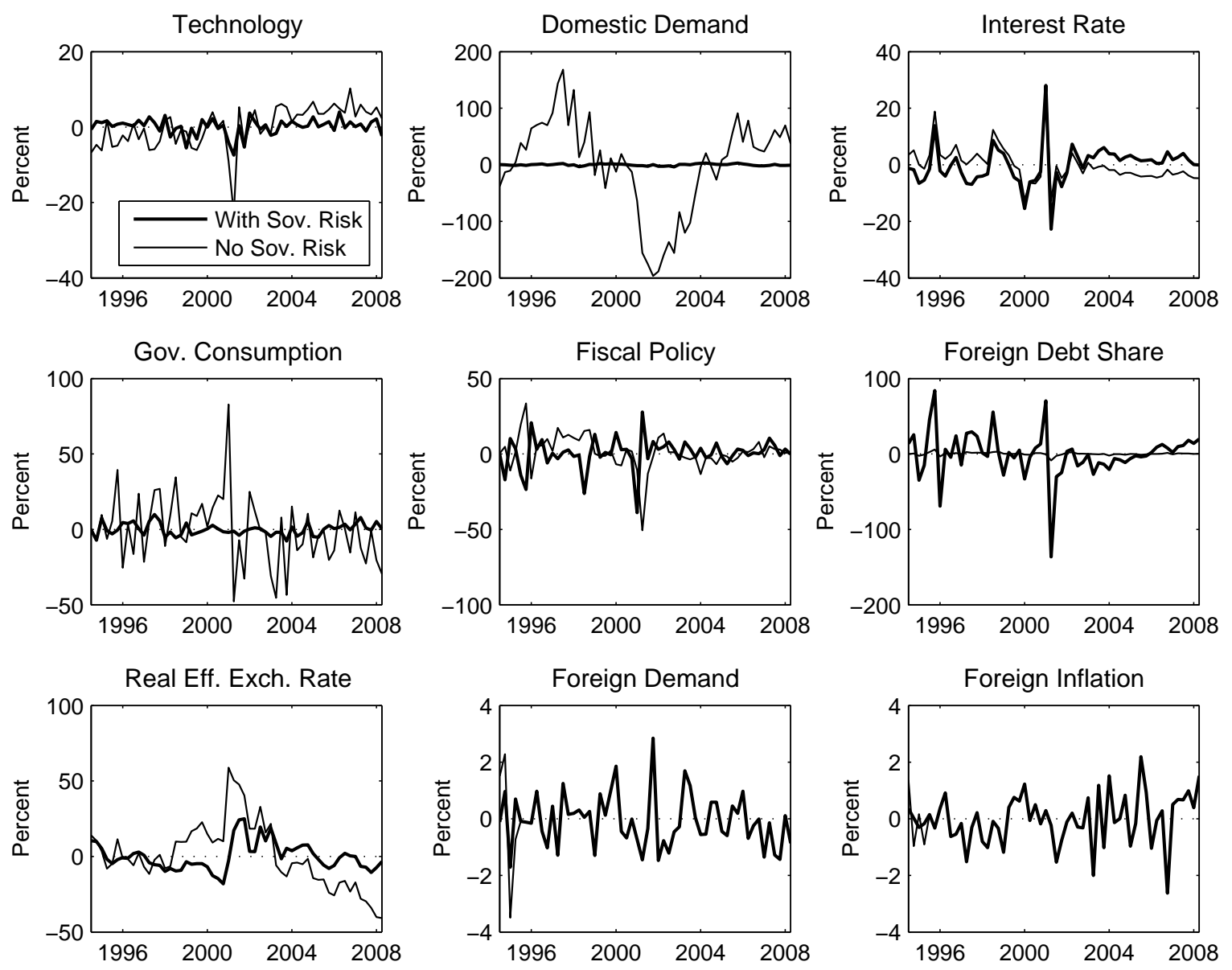

Figure 3: Estimated structural innovations with and without sovereign risk (percentage points). Notes. The innovations are estimates implied by the Kalman smoother at the posterior mean.

forecast output, inflation and government debt fairly well, it is obvious that the model with sovereign risk implies better forecasts of private consumption and government consumption in particular, but also of the real exchange rate and the nominal interest rate.

The obtained fit of the basic model in some directions thus comes at the cost of inferior forecasts in other directions. For example, large demand shocks may help to match the dynamics of the real interest rate (as discussed below), but they imply bad forecasts for consumption. The reason is that expected consumption repeatedly underpredicts actual consumption if there are long sequences of unexpected positive demand shocks. The basic model also generates large government consumption shocks (see Figure 3) in order to match the dynamics of inflation and the nominal interest rate, which works through the inflationary impact of expansionary fiscal shocks. However, this comes at the cost of bad forecasts of government consumption.

Table 3 reports mean forecast errors (MFE) and root mean squared forecast errors 

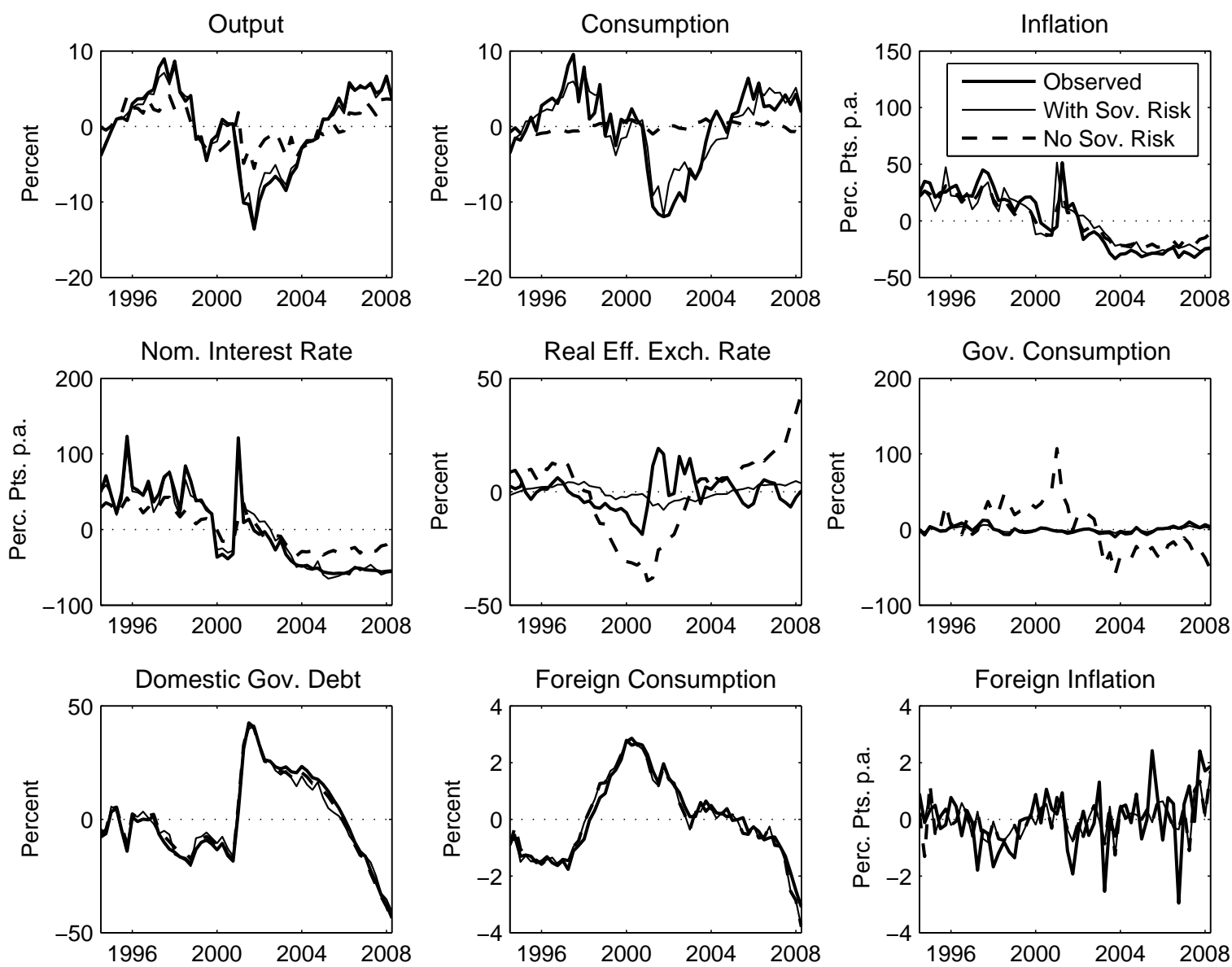

Figure 4: Observed data and one-step ahead forecasts from the models with and without sovereign risk. Notes. Quarterly data, 1994:3-2008:2; one-step ahead forecasts are estimates implied by the Kalman filter at the posterior mean; real variables are measured in percentage deviations from a linear trend, nominal variables are demeaned and in annualized percentage terms.

(RMSFE) which were computed based on the one-step ahead forecasts.21 The RMSFE are useful to judge the overall predictive performance of the two model versions. The MFE help to judge whether any variable is repeatedly over- or underpredicted. The latter indicate that the basic model tends to underpredict domestic consumption, inflation and the real exchange rate, but overpredicts government consumption. The mean forecast errors are however much closer to zero in the augmented model, for almost all variables. Similarly, the RMSFE of the augmented model are (significantly) smaller for almost all variables. As for the business cycle moments, exceptions are in case of the MFE the interest rate and in case of the RMSFE inflation and debt. We postpone the interpretation of these results to Section 4.2. In sum, the model with sovereign risk is clearly preferable in terms of forecasting performance to the

\footnotetext{
${ }^{21}$ The formulas are MFE $=T^{-1} \sum_{t=1}^{T} F_{t}$ and RMSFE $=\sqrt{T^{-1} \sum_{t=1}^{T} F_{t}^{2}}$, where $F_{t}$ is the one-step ahead forecast error.
} 
Table 3: One-step ahead forecast errors. ${ }^{\text {a }}$

\begin{tabular}{lrrrrr}
\hline & \multicolumn{2}{c}{$\begin{array}{c}\text { Mean forecast } \\
\text { error MFE }\end{array}$} & & \multicolumn{2}{c}{$\begin{array}{c}\text { Root mean squared } \\
\text { forecast error RMSFE }\end{array}$} \\
\cline { 2 - 3 } \cline { 5 - 6 } & With sov. risk & No sov. risk & & With sov. risk & No sov. risk \\
\hline Output & -0.00 & 0.00 & & 0.75 & 3.66 \\
Consumption & 0.00 & 0.04 & & 2.14 & 5.23 \\
Inflation & 0.05 & 0.08 & & 13.26 & 8.90 \\
Interest rate & 0.12 & 0.11 & & 8.96 & 30.33 \\
Real exch. rate & -0.02 & 0.40 & & 8.97 & 18.91 \\
Gov. consumption & 0.00 & -1.19 & & 2.42 & 23.43 \\
Domestic debt & 0.03 & -0.06 & & 3.14 & 1.81 \\
For. consumption & 0.03 & 0.01 & & 0.27 & 0.28 \\
For. inflation & -0.01 & 0.01 & & 0.98 & 1.00 \\
\hline
\end{tabular}

${ }^{a}$ The forecast errors $F_{t}$ are computed as the difference between the observed variable $Y_{t}$ and its one-step ahead forecast $Y_{t}^{f}$ as $F_{t}=Y_{t}-Y_{t}^{f}$, where $Y_{t}$ and $Y_{t}^{f}$ are measured in percentage terms.

b The mean forecast errors are computed according to the formula $\mathrm{MFE}=T^{-1} \sum_{t=1}^{T} F_{t}$.

c The mean squared forecast errors are computed according to the formula RMSFE = $\sqrt{T^{-1} \sum_{t=1}^{T} F_{t}^{2}}$

underlying basic model.

\subsubsection{Default premia and effective interest rates}

Why does the model with sovereign risk provide a significantly better fit to the observed data or, conversely, why does the data clearly reject the basic model? In order to provide an intuition, notice that combining equations (16) and (24) yields

$$
\varepsilon_{c, t}-\sigma \hat{c}_{t}=E_{t}\left(\varepsilon_{c, t+1}-\sigma \hat{c}_{t+1}\right)+\hat{R}_{H, t}-E_{t} \hat{\pi}_{t+1}-\frac{1}{1-\bar{\delta}} E_{t} \tilde{\delta}_{t+1}
$$

or, using that $E_{t} \varepsilon_{c, t+1}=0$ and re-writing:

$$
\sigma\left(E_{t} \hat{c}_{t+1}-\hat{c}_{t}\right)=\hat{R}_{H, t}-E_{t} \hat{\pi}_{t+1}-\frac{1}{1-\bar{\delta}} E_{t} \tilde{\delta}_{t+1}-\varepsilon_{c, t}
$$

Suppose that expected consumption growth $E_{t} \hat{c}_{t+1}-\hat{c}_{t}$ shows "different" dynamics than the expected real interest rate $\hat{R}_{H, t}-E_{t} \hat{\pi}_{t+1}$. Indeed, according to both models, estimated consumption growth was low in the first half of the sample whereas the real interest rate was relatively high (compare Figure 5 and Figure 7). In principle, there are three ways in which such dynamics could be reconciled with (37):

1. Suppose that $E_{t} \tilde{\delta}_{t+1}=0$ for all $t$. Positive demand shocks $\varepsilon_{c, t}$ could make (37) hold if $E_{t} \hat{c}_{t+1}-\hat{c}_{t}$ is temporarily low relative to $\hat{R}_{H, t}-E_{t} \hat{\pi}_{t+1}$. For example, in the case of a 

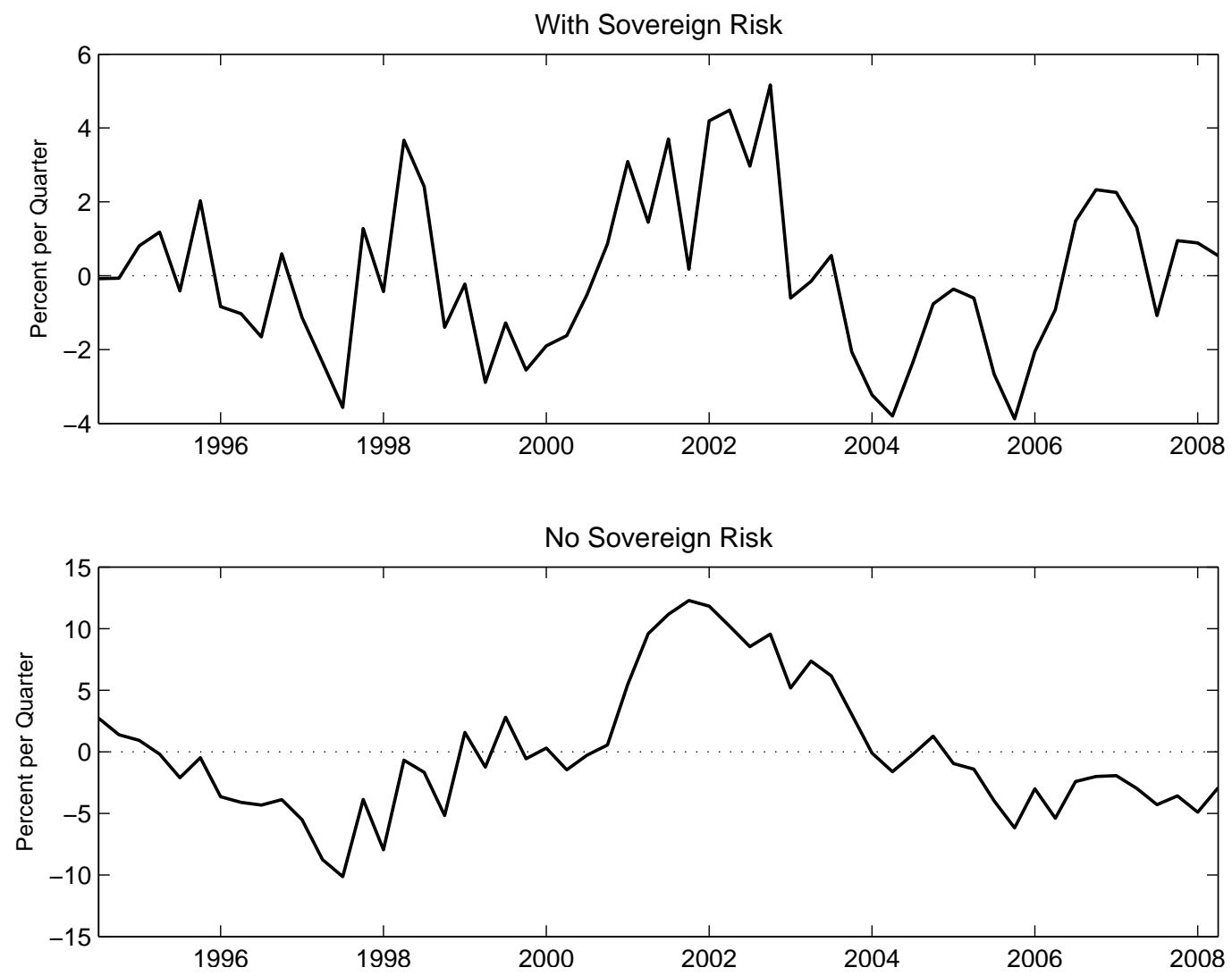

Figure 5: Estimated expected consumption growth with and without sovereign risk (in percentage deviations from steady state). Notes. Expected consumption growth $E_{t} \hat{c}_{t+1}-\hat{c}_{t}$ is estimated using the Kalman smoother at the posterior mean.

positive demand shock, households would save less even if the real interest rate is high since they have a temporary preference for higher consumption.

2. Alternatively, set both $E_{t} \tilde{\delta}_{t+1}=0$ and $\varepsilon_{c, t}=0$ for all $t$. A relatively large value on the inverse intertemporal substitution elasticity $\sigma$ would increase the households' preferences for a smooth consumption path, even if the real interest rate is not smooth.

3. Finally, with relatively small demand shocks and a moderate value of $\sigma$, a high expected default rate can balance (37). Households would invest less when the real interest rate is high due to higher default fears, and vice versa.

A combination of all three explanations seems relevant for understanding our estimation results. First, large demand shocks occur in the model without sovereign risk whereas the model with sovereign risk requires much smaller shocks, as indicated by Figure 6, which shows the smoothed demand shocks from both models. Second, the estimated value of $\sigma$ is more than 25 times higher in the model without sovereign risk. And third, we conclude from Figure 7 that default premia were relatively high before the monetary reforms in 2001 but 

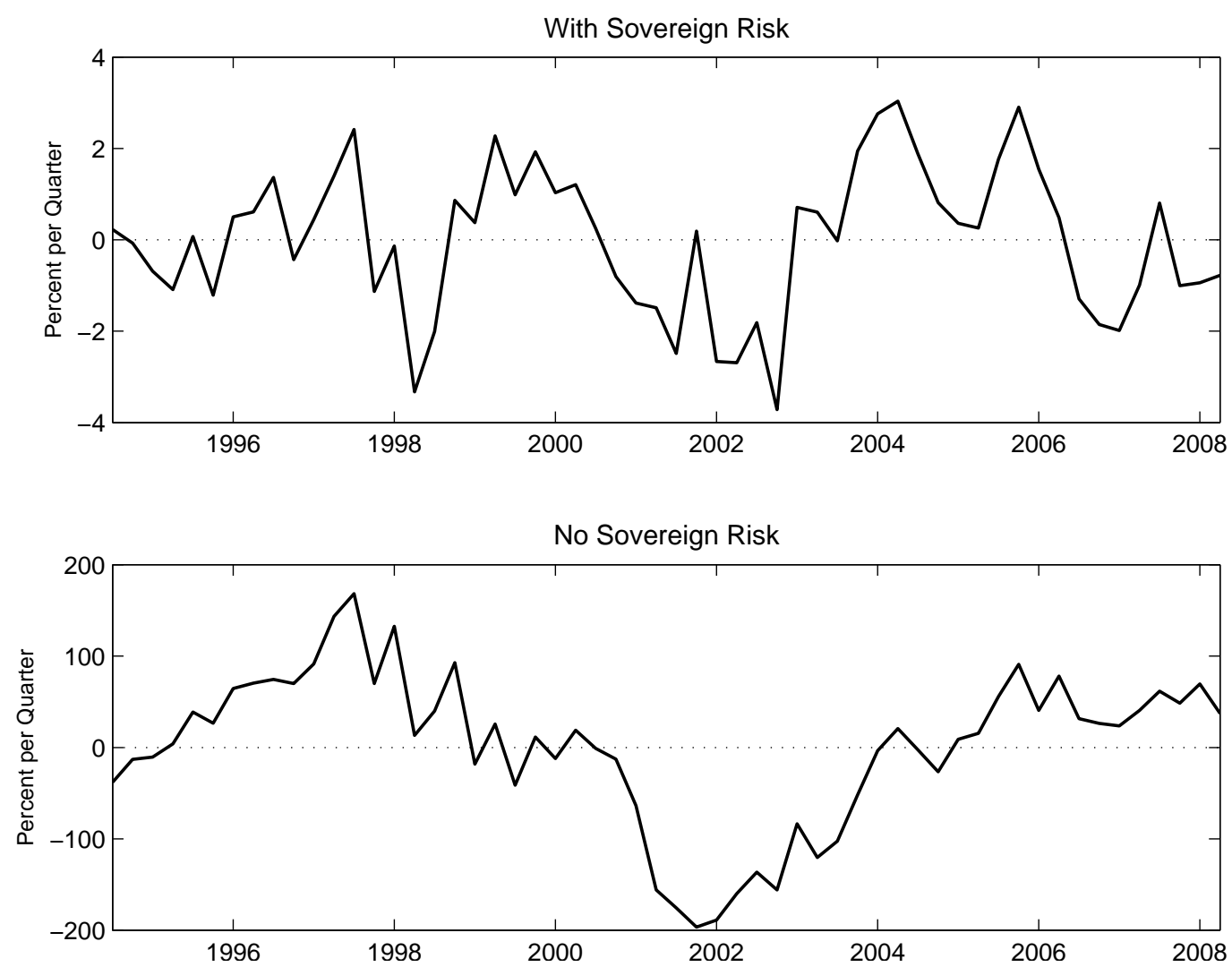

Figure 6: Estimated demand shocks $\varepsilon_{c, t}$ with and without sovereign risk. Notes. The shocks are estimates implied by the Kalman smoother at the posterior mean.

they have declined since then. Therefore, the effective real interest rate net of default risk $\hat{R}_{H, t}-E_{t} \hat{\pi}_{t+1}-E_{t} \tilde{\delta}_{t+1} /(1-\bar{\delta})$ shows much smoother dynamics than the actual real rate, which are easier to reconcile with the expected consumption growth.

\subsubsection{Variance decomposition}

The importance of alternative structural shocks in driving the variation of the observed data as well as the (estimated) expected default rate is analyzed next. Table 4 reports their unconditional posterior variance decomposition, distinguishing between economic shocks and policy shocks 22

The results show that economic shocks are the main driving force of output, private consumption and the real exchange rate in both versions of the model. However, overall the economic shocks are more important in the model without sovereign risk. With sovereign risk, about $50-60 \%$ of the variation in inflation and the nominal interest rate is attributed to policy shocks, and here especially the fiscal policy shock $\varepsilon_{\tau}$ and the government consumption shock $\varepsilon_{g}$, whereas the basic model does not assign a dominant role to those shocks. The

\footnotetext{
${ }^{22}$ The economic shocks are $\left\{\varepsilon_{a}, \varepsilon_{c}, \varepsilon_{c^{*}}, \varepsilon_{\pi^{*}}, \varepsilon_{q}\right\}$ and the policy shocks are $\left\{\varepsilon_{R}, \varepsilon_{\tau}, \varepsilon_{g}\right\}$.
} 
Table 4: Posterior variance decomposition of observed variables and estimated default rate. ${ }^{\text {a }}$

\begin{tabular}{|c|c|c|c|c|c|c|c|c|c|c|}
\hline & Output & Cons. & Inflation & Int. rate & Exch. rate & Gov. cons. & Dom. debt & For. cons. & For. infl. & Default rate \\
\hline \multicolumn{11}{|c|}{ With sovereign risk: economic shocks } \\
\hline Technology $\varepsilon_{a}$ & 98.9 & 83.0 & 35.6 & 36.6 & 10.1 & 0.0 & 26.8 & 0.0 & 0.0 & 33.8 \\
\hline Dom. demand $\varepsilon_{c}$ & 0.6 & 14.9 & 0.2 & 0.2 & 0.2 & 0.0 & 0.1 & 0.0 & 0.0 & 0.2 \\
\hline For. demand $\varepsilon_{c^{*}}$ & 0.1 & 1.1 & 3.0 & 3.1 & 1.3 & 0.0 & 2.3 & 73.1 & 15.0 & 3.0 \\
\hline For. prices $\varepsilon_{\pi^{*}}$ & 0.1 & 0.4 & 1.2 & 1.2 & 0.5 & 0.0 & 1.0 & 26.8 & 85.0 & 1.2 \\
\hline Exch. rate $\varepsilon_{q}$ & 0.0 & 0.0 & 0.0 & 0.0 & 87.8 & 0.0 & 0.0 & 0.0 & 0.0 & 0.0 \\
\hline \multicolumn{11}{|c|}{ With sovereign risk: policy shocks } \\
\hline Int. rate $\varepsilon_{R}$ & 0.3 & 0.2 & 4.2 & 1.4 & 0.0 & 0.0 & 1.1 & 0.0 & 0.0 & 1.4 \\
\hline Gov. cons. $\varepsilon_{g}$ & 0.1 & 0.3 & 20.3 & 20.9 & 0.0 & 100.0 & 15.9 & 0.0 & 0.0 & 20.9 \\
\hline Fiscal policy $\varepsilon_{\tau}$ & 0.0 & 0.0 & 35.6 & 36.6 & 0.0 & 0.0 & 28.9 & 0.0 & 0.0 & 39.5 \\
\hline For. debt share $\varepsilon_{f}$ & 0.0 & 0.0 & 0.0 & 0.0 & 0.0 & 0.0 & 23.9 & 0.0 & 0.0 & 0.0 \\
\hline Total $^{\mathrm{b}}$ & 0.4 & 0.5 & 60.1 & 48.9 & 0.0 & 100.0 & 69.8 & 0.0 & 0.0 & 61.8 \\
\hline Technology $\varepsilon_{a}$ & 4.4 & 0.5 & 30.4 & 22.0 & 2.4 & 0.0 & 1.7 & 0.0 & 0.0 & - \\
\hline Dom. demand $\varepsilon_{c}$ & 15.8 & 95.2 & 0.9 & 0.7 & 0.0 & 0.0 & 0.0 & 0.0 & 0.0 & - \\
\hline For. demand $\varepsilon_{c^{*}}$ & 45.5 & 2.8 & 43.6 & 31.5 & 47.0 & 0.0 & 19.6 & 73.2 & 15.0 & - \\
\hline For. prices $\varepsilon_{\pi^{*}}$ & 17.1 & 1.0 & 17.2 & 12.4 & 17.5 & 0.0 & 3.0 & 26.8 & 85.0 & - \\
\hline Exch. rate $\varepsilon_{q}$ & 0.0 & 0.0 & 0.0 & 0.0 & 30.6 & 0.0 & 0.0 & 0.0 & 0.0 & - \\
\hline Total & 82.8 & 99.5 & 92.1 & 66.6 & 97.5 & 0.0 & 24.3 & 100.0 & 100.0 & - \\
\hline \multicolumn{11}{|c|}{ No sovereign risk: policy shocks } \\
\hline Int. rate $\varepsilon_{R}$ & 3.3 & 0.4 & 2.8 & 29.7 & 1.7 & 0.0 & 13.6 & 0.0 & 0.0 & - \\
\hline Gov. cons. $\varepsilon_{g}$ & 13.9 & 0.1 & 5.2 & 3.7 & 0.7 & 100.0 & 10.5 & 0.0 & 0.0 & - \\
\hline Fiscal policy $\varepsilon_{\tau}$ & 0.0 & 0.0 & 0.0 & 0.0 & 0.0 & 0.0 & 51.4 & 0.0 & 0.0 & - \\
\hline For. debt share $\varepsilon_{f}$ & 0.0 & 0.0 & 0.0 & 0.0 & 0.0 & 0.0 & 0.4 & 0.0 & 0.0 & - \\
\hline Total & 17.2 & 0.5 & 8.0 & 33.4 & 2.4 & 100.0 & 75.9 & 0.0 & 0.0 & - \\
\hline
\end{tabular}

${ }^{a}$ Table entries refer to contribution to unconditional variance (in percent) at the posterior mean.

b Some of the totals do not sum up to $100 \%$ due to rounding errors. 


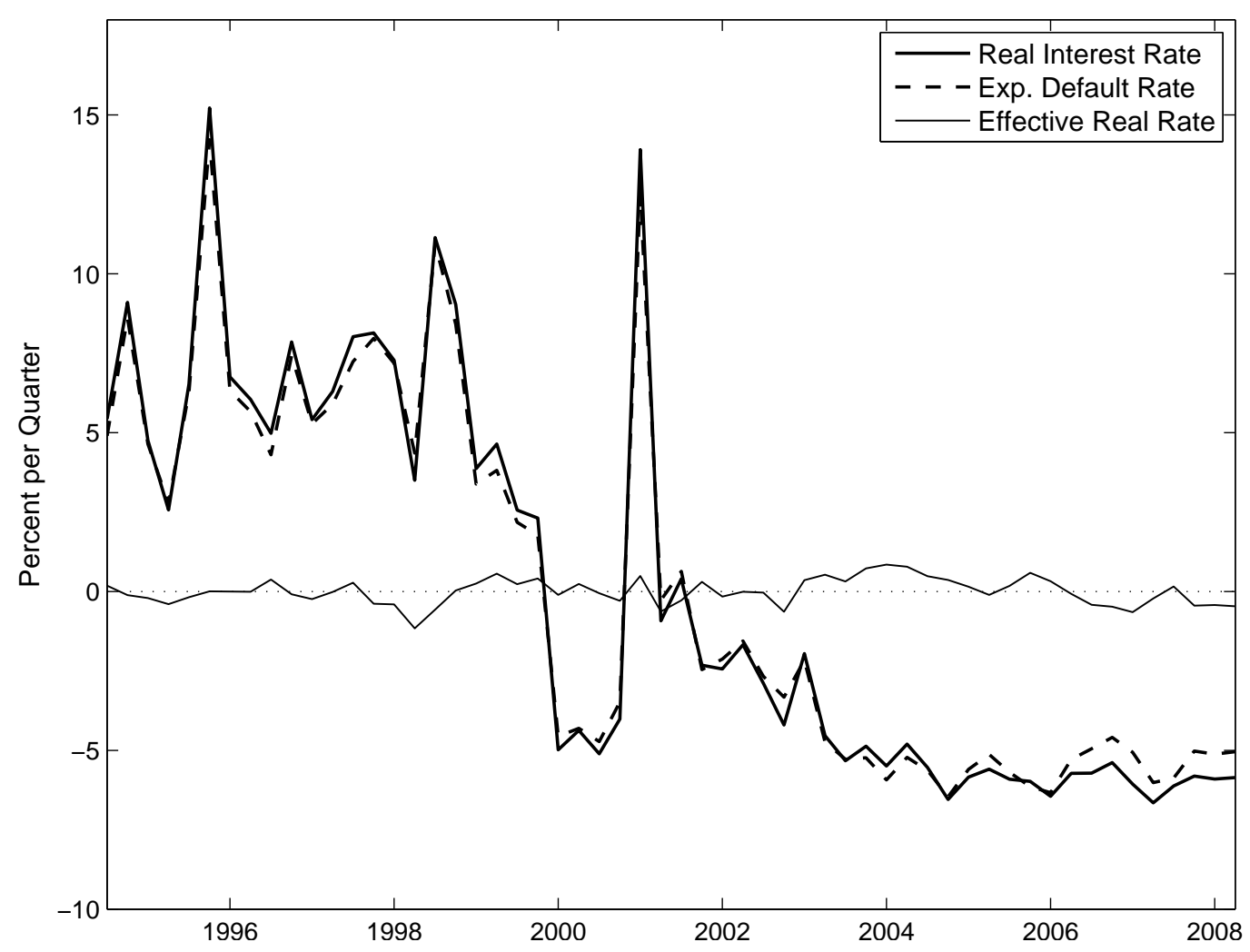

Figure 7: Estimated expected real interest rate $\left(\hat{R}_{H, t}-E_{t} \hat{\pi}_{t+1}\right)$, expected default rate $\left(E_{t} \tilde{\delta}_{t+1}\right)$ and effective real interest rate $\left(\hat{R}_{H, t}-E_{t} \hat{\pi}_{t+1}-(1-\bar{\delta})^{-1} E_{t} \tilde{\delta}_{t+1}\right)$. Notes. The variables are estimates implied by the Kalman smoother at the posterior mean; the real interest rate and the real effective interest rate are reported as quarterly percentage deviations from steady state; the default rate is measured in absolute deviations (in percentage points) from its steady state value.

interest rate shock $\varepsilon_{R}$, on the other hand, becomes less important in explaining variation in the nominal interest rate in the model with sovereign risk.

In terms of the driving forces of the expected default rate, it turns out that economic shocks contribute $38 \%$ and policy shocks contribute $62 \%$ to its variation. Among the economic shocks, technology shocks are again most important. Among the policy shocks, the fiscal policy shocks contributes most variation, about $40 \%$, whereas the government consumption and the interest rate shock contribute about $21 \%$ and $1 \%$, respectively. These results indicate that a reduction in the volatility of policy shocks (especially fiscal shocks) has helped to reduce the variability of expected default rates over time (compare Figures 3 and 7).

\subsection{Counterfactual experiments and amplification of shocks}

In this subsection we first present several counterfactual experiments in order to investigate the importance of (and to gain intuition for) particular elements of the model in explaining the 
dynamics of the model and hence the observed data. Moreover, we analyze the implications of alternative fiscal and monetary policies. Then we present the estimated impulse response functions from the basic and the augmented model computed at the posterior mean estimates of the structural parameters which here jointly differ across the two models. In all cases, we compare the impulse responses of selected variables to a unitary negative technology shock where the shock is normalized to have the estimated persistence from the model with sovereign risk in order to ensure comparability 23

\subsubsection{Counterfactual experiments}

All experiments are based on the estimated model with sovereign risk, which we refer to as the benchmark model 24 We change one structural parameter at a time. In particular, (i) the default elasticity $\Phi$ is set to zero, (ii) the degree of openness $\vartheta$ is set to zero, (iii) the foreign debt share $\bar{f}$ is set to zero, (iv) the inverse intertemporal substitution elasticity $\sigma$ is set to 15.85, its posterior mean estimate in the basic model, (v) the fiscal feedback $\kappa$ is doubled and (vi) the monetary feedback $\alpha_{\pi}$ is doubled. For expositional purposes, we first discuss experiment (i), the model without sovereign risk, before we turn to the benchmark model with sovereign risk.

Figure 8 shows the impulse responses for experiments (i), (ii), (iii) and (iv). When the default elasticity $\Phi$ is set to zero (experiment (i), thick dashed line) there is no expected default (i.e. Ricardian equivalence holds). The negative technology shock causes a rise in intermediate goods firms' marginal costs. The firms react by increasing prices, which leads to an appreciation of the real exchange rate. Domestic consumption therefore falls, due to international risk sharing and expenditure switching of domestic and foreign households, and so does domestic output. The monetary authority reacts to higher inflation by increasing the nominal interest rate. Government debt falls initially, due to the direct beneficial exchange rate effect on foreign debt and the fact that government purchases of domestic goods become cheaper due to the real appreciation. Thereafter, government debt shows a persistent increase due to higher debt service obligations resulting from the higher nominal interest rate.

Under sovereign risk (benchmark model, solid line) the real value of debt affects the effective rate of return and thus alters those dynamics through various channels. As in case (i), higher inflation leads to higher nominal interest rates and hence to higher debt service

\footnotetext{
${ }^{23}$ The parameter $\rho_{a}$ is thus set to 0.91 in all models.

${ }^{24}$ We choose the augmented model as the benchmark since the basic model is clearly rejected by the data. Moreover, the augmented model allows analyzing the effects of foreign currency denominated debt and changes of the policy parameters, both in the presence of sovereign risk.
} 

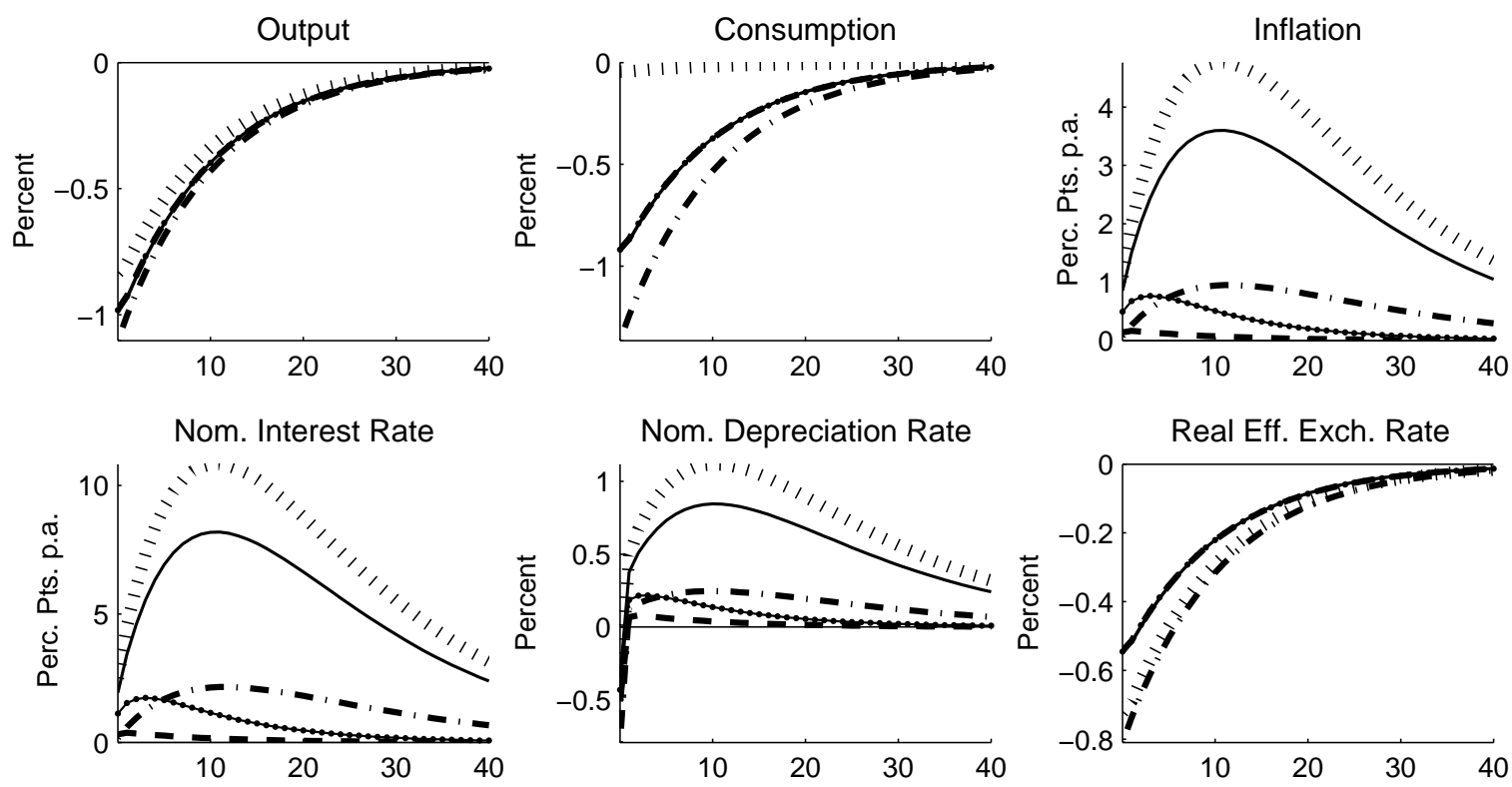

Domestic Gov. Debt

Expected Default Rate
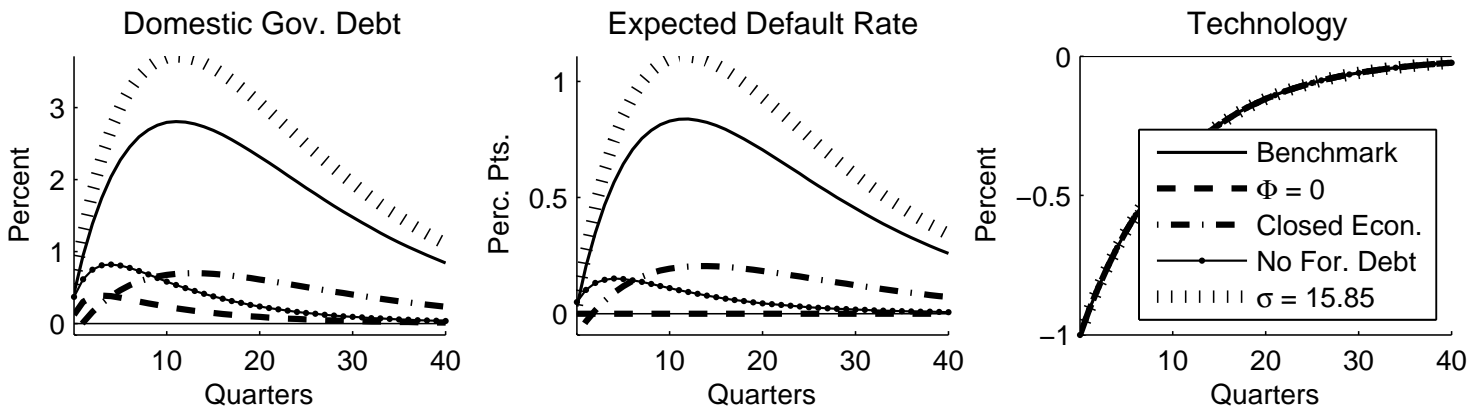

Figure 8: Estimated and counterfactual impulse responses due to a technology shock based on the model with sovereign risk. Notes. Technology shock is normalized to $1 \%$; estimated impulse responses are calculated at the posterior mean and counterfactual impulse responses are calculated by changing one parameter at a time; real variables are measured in percentage deviations from steady state, nominal variables in absolute (annual) percentage point deviations from steady state.

obligations and debt. However, savings tend to be lower and current domestic consumption tends to be higher than in case (i) due to the negative feedback from debt on its return (see equations 24 and 26), spurring inflationary pressures. In order to contain inflation, the central bank needs to increase the nominal interest rate by more than in case (i), which then reduces the tendency of current domestic consumption to rise. Higher nominal rates in turn imply higher debt servicing costs, higher debt levels and thus increasing expected default rates which tend to lower the expected return on debt and hence eventually lead to further pressures on demand and inflation. Hence, the initial increase of inflation is amplified via the negative feedback from debt on its return, pushing up nominal variables and debt.

In an open economy, demand and inflationary pressures are even larger due to the presence of the exchange rate channel. Here, the pressure on domestic current consumption from the 
negative feedback from debt on its return feeds into pressures on the real exchange rate due to international risk sharing (see equation 23). A real depreciation would lead to expenditure switching of domestic households and increasing demand of foreign households for home goods. Moreover, domestic households would demand a higher nominal wage since the price level of aggregate consumption rises due to higher prices of imported goods. Hence, in a open economy the central bank has to raise nominal interest rate by more than in a closed economy in order to maintain the additional demand pressures from depreciationary effects of the real exchange rate.

The benchmark model and experiment (i) show that the presence of sovereign risk in an open economy may considerably amplify the fluctuations of nominal variables and debt. In addition to improving the fit of the consumption Euler equation (see Section 4.1), including sovereign risk into the model thus helps to account for the high volatility of nominal variables and debt in the data. Put differently, it is not only the variability of the default premium which helps to improve the fit of the model but also its pure existence.

In a closed economy (experiment (ii), dash-dotted line) the impact of the technology shock on the inflation and the nominal interest rate is significantly muted, such that the debt response and the reaction of the default rate are also smaller 25 The reason is that the additional pressure on aggregate demand via the exchange rate is shut down in that case. This experiment shows that the presence of sovereign risk also alters the dynamics of a closed economy, but that the effects of sovereign risk are amplified in an open economy via the exchange rate channel.

Similarly, without foreign debt (experiment (iii), solid line with dots) the increase in inflation, the nominal interest rate and debt is muted. Without foreign currency denominated debt, the pressure on the real exchange rate does not trigger additional fears of default due to fears of debt revaluation (see equations 24, 26 and 28). Moreover, the devaluating effect of increases of domestic inflation on the stock of real debt is more pronounced if debt is only denominated in domestic currency. Interestingly, the dynamics without foreign debt are quantitatively more similar to the dynamics without sovereign risk (experiment i) than to the benchmark model, for the given parameter values.

For high values of the inverse intertemporal substitution elasticity $\sigma$ (experiment (iv), bars) the response of consumption to an increase of the nominal interest rate is substantially muted since households have strong preferences for a smooth consumption path. The effec-

\footnotetext{
${ }^{25}$ Notice that the definitions of the nominal depreciation rate and the real exchange rate become meaningless for $\vartheta=0$.
} 
tiveness of high nominal rates to maintain pressures on aggregate demand is reduced such that higher nominal rates are required. Higher nominal rates in turn imply higher actual debt service obligations and hence expected default rates, explaining the amplified responses for high values of $\sigma$.

A priori, it is not clear which policy is superior in terms of stabilizing nominal variables, debt and expected default rates, stronger fiscal or stronger monetary feedbacks. A stronger fiscal feedback is expected to lead to a faster reduction in government debt at the cost of approaching critical tax levels. The impact on the expected default rate is therefore ambiguous. A stronger monetary feedback may better contain demand pressures, but they imply higher actual debt service obligations and hence fears of default.

The results reported in Figure 9 show that due to an increase in the fiscal feedback coefficient $\kappa$ from 0.53 to 1.06 (experiment (v), solid line with dots) the reduction in government debt via higher taxes occurs faster. The increase in the expected default rate is therefore weaker, which leads to lower demand pressure and inflation and thus a smaller increase in the nominal interest rate. Under a higher monetary feedback, i.e. an increase of $\alpha_{\pi}$ from 2.1 to 4.2 (experiment (vi), solid-dotted line) inflation expectations are contained. Hence, demand pressures do not feed into higher inflation which reduces the need for the central bank to

raise actual nominal interest rates 26 However, there is no reduction in the response of the default rate but rather a slight increase since the devaluating effect of inflation on the real stock of debt is smaller.

We conclude that the destabilizing dynamics of sovereign risk discussed by Blanchard (2005) and Schabert and van Wijnbergen (2010) do have practical relevance. However, both more active monetary and higher fiscal debt feedbacks on taxes can have stabilizing effects on nominal interest rates, inflation and government debt. A more active stance of monetary policy, by maintaining inflation expectations, reduces the need for high nominal interest rates. Default premia can however be larger under more active monetary policy whereas they unambiguously decline with higher fiscal feedbacks. Hence, if an economy is subject to sovereign risk solid fiscal policy is an effective device for stabilizing nominal interest rates, inflation and debt, and the clearly preferable policy for stabilizing expected default rates.

\subsubsection{Amplification of shocks}

After analyzing particular elements of the model in isolation, we now discuss the estimated impulse response functions from both models computed at the posterior mean estimates of the

\footnotetext{
${ }^{26}$ The same holds in a closed economy setting, not reported here.
} 

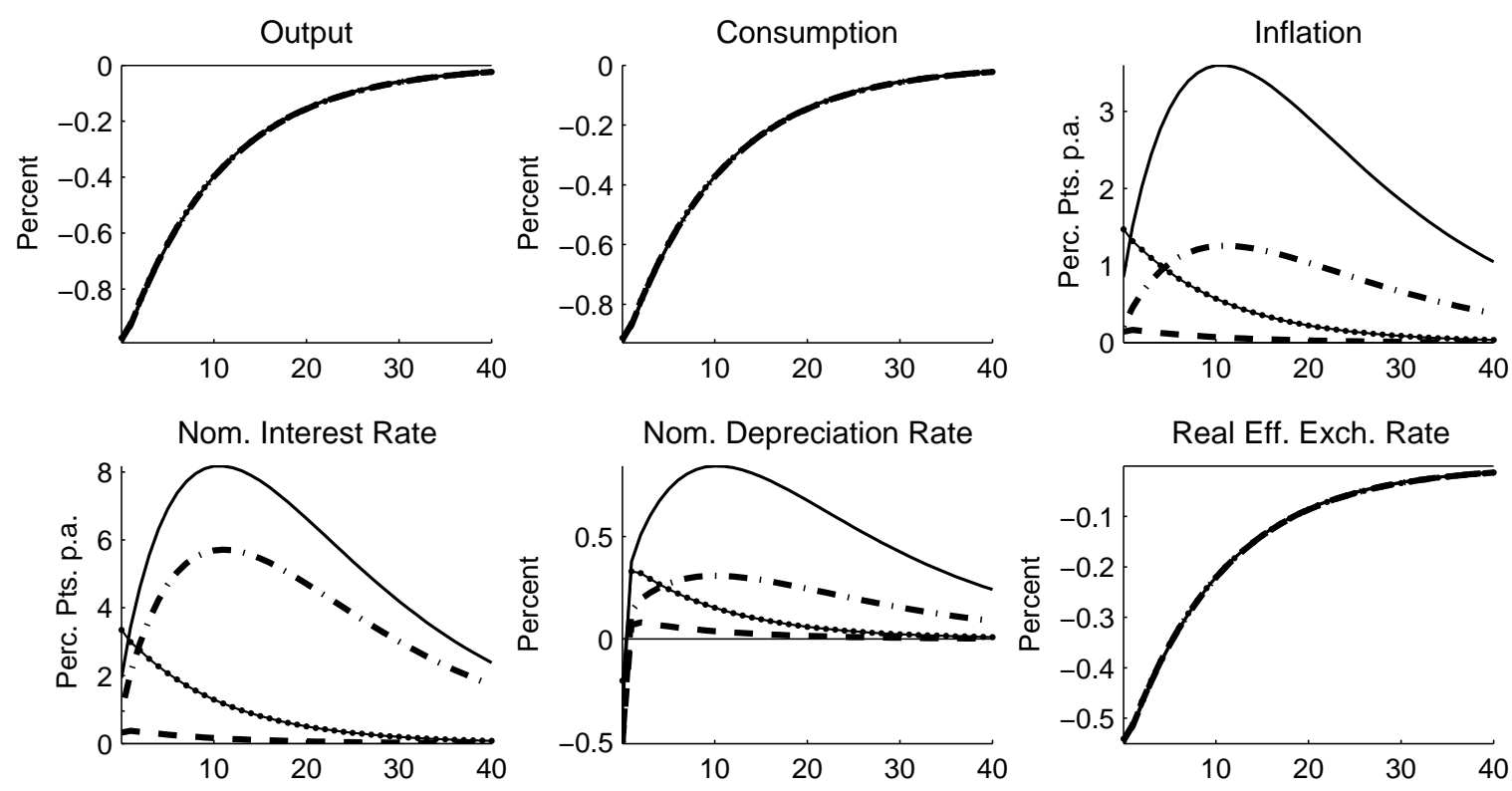

Domestic Gov. Debt
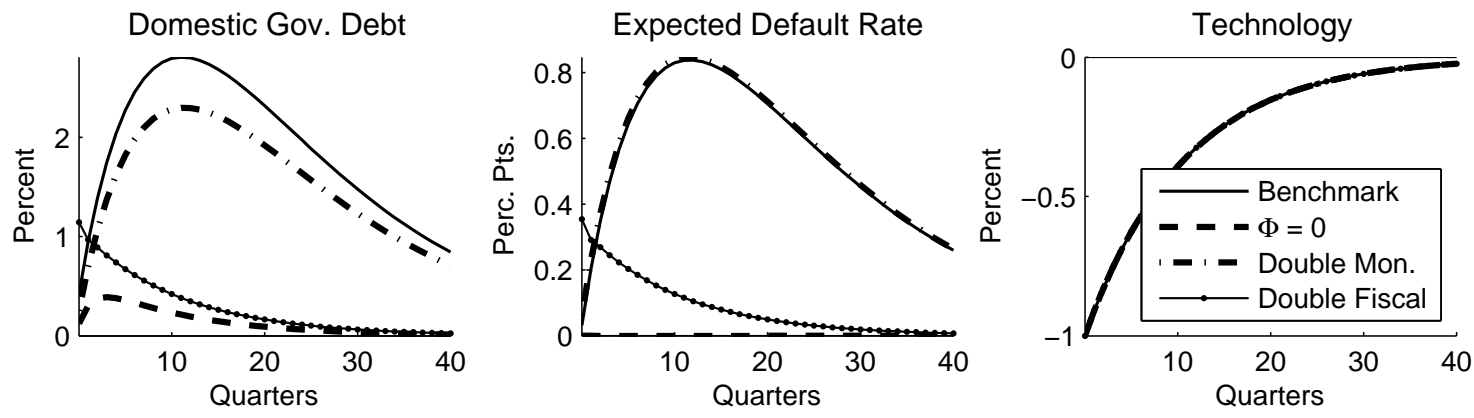

Figure 9: Estimated and counterfactual impulse responses due to a technology shock based on the model with sovereign risk, policy feedbacks. Notes. Technology shock is normalized to $1 \%$; estimated impulse responses are calculated at the posterior mean and counterfactual impulse responses are calculated by changing one parameter at a time; real variables are measured in percentage deviations from steady state, nominal variables in absolute (annual) percentage point deviations from steady state.

structural parameters which now jointly differ across models. The dashed line in Figure 10 shows the impulse responses due to a unitary negative technology shock of the basic model without sovereign risk. As above, the negative technology shock causes a rise in inflation and an appreciation of the real exchange rate. Domestic consumption and output fall. The monetary authority increases the nominal interest rate, government debt falls initially and then shows a persistent increase due to higher debt service obligations resulting from the higher interest rate.

Under sovereign risk (solid line), the real value of debt affects the effective rate of return, as discussed above. In particular, the amplification of the responses of inflation, the nominal interest rate, domestic debt and the expected default rate can mainly be attributed to the presence of sovereign risk, i.e. to the fact that $\Phi>0$. The different responses of consumption, 

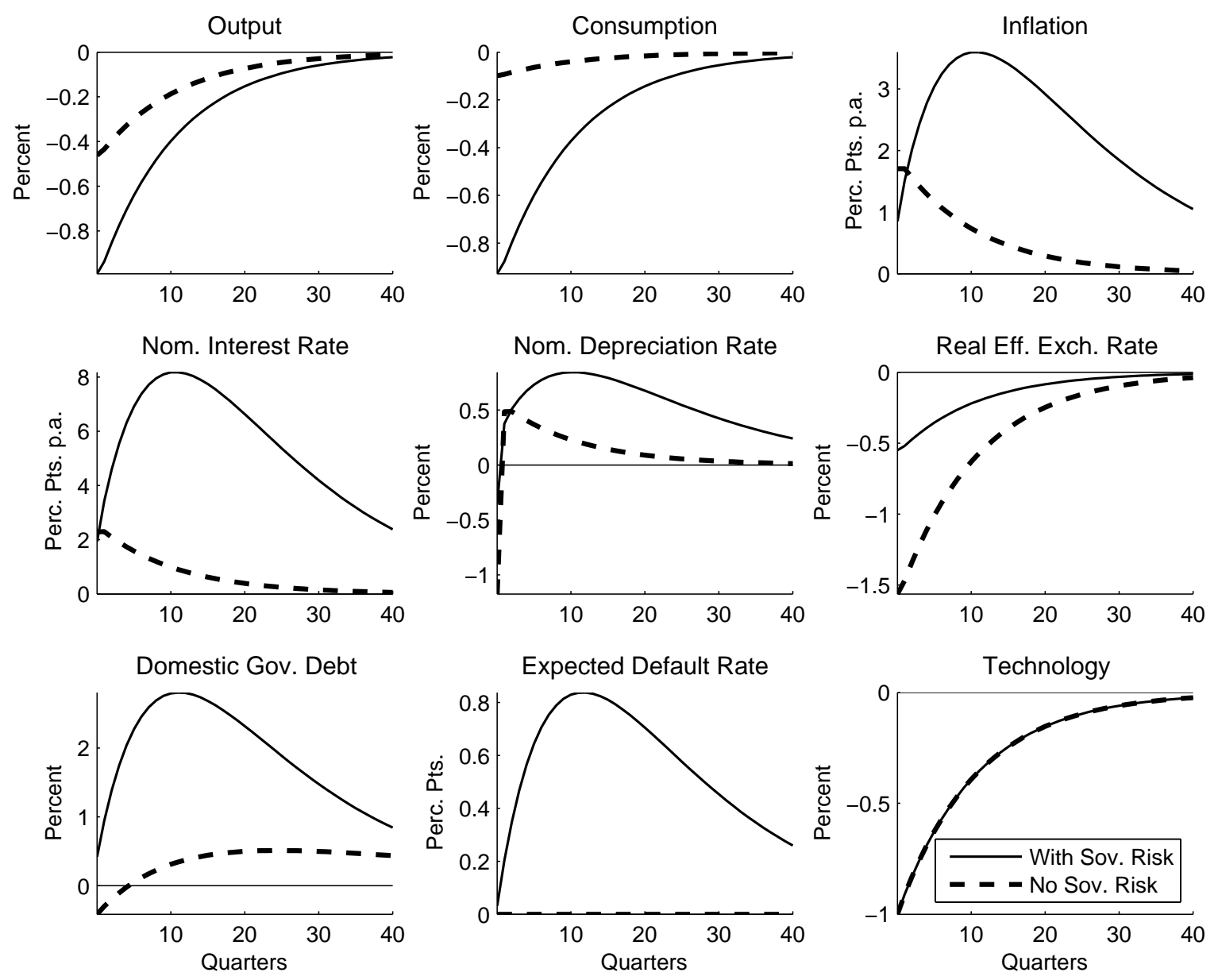

Figure 10: Estimated impulse responses due to technology shocks in the models with and without sovereign risk. Notes. Technology shock is normalized to $1 \%$ and to have persistence as estimated in the model with sovereign risk; impulse responses are calculated at the posterior mean; real variables are measured in percentage deviations from steady state, nominal variables in absolute (annual) percentage point deviations from steady state.

output and the real exchange rate seem to be mainly driven by the lower value of the inverse intertemporal substitution elasticity $\sigma$. A low value for $\sigma$ implies a more pronounced response of consumption to movements in the real effective interest rate. However, the effect on the real exchange rate is muted since variations in domestic consumption only feed into small variations of the real exchange rate, given the low value of $\sigma$ (as can be seen from equations [16] and 23). Finally, the higher share of imports tends to amplify both the effects of sovereign risk on nominal variables and government debt and the response of consumption.

In sum, comparing these results to the impulse responses in Figures 8 and 9 shows that the differences between the dynamics of the estimated basic and the estimated augmented model are due to the fact that all parameters differ across estimated models but not from the addition of sovereign risk in isolation. 


\subsection{Sensitivity checks}

As a final step of the analysis, we estimate alternative versions of the benchmark model with sovereign risk. Table 5 compares the parameter estimates. First, instead of estimating the standard deviation of the measurement error on the real effective exchange rate $\sigma_{q}$, it is calibrated to 0.05 , i.e. its prior mean 27 The estimated inverse intertemporal substitution elasticity $\sigma$, the degree of openness $\vartheta$, and the degree of price stickiness $\phi$ change slightly, but the remaining estimates remain almost unaffected.

Second, an exchange rate stabilization term is introduced in the monetary authority's reaction function. The reason is that the CBRT only moved to explicit inflation targeting with the economic reforms introduced in 2001. Before that, it pursued a crawling peg exchange rate targeting policy (see Gormez and Yilmaz, 2007). We attempt to capture this fact by the following modification of (4):

$$
\frac{R_{H, t}}{R_{H}}=\left(\frac{\pi_{t}}{\pi}\right)^{\alpha_{\pi}}\left(\frac{q_{t}}{q}\right)^{\alpha_{q}} \exp \left(\varepsilon_{R, t}\right)
$$

where again $\varepsilon_{R, t} \sim N I D\left(0, \sigma_{R}^{2}\right)$ and the feedback $\alpha_{q}$ indicates the strength of the monetary authority's reaction to exchange rate movements 28 As the inflation feedback, the exchange rate feedback is assumed to be non-negative, i.e. the monetary authority reacts to a real depreciation by increasing the nominal interest rate 29 The exchange rate feedback is motivated by Lubik and Schorfheide's (2007) observation that many central banks in small open economies do target exchange rate movements via a Taylor rule. The estimation results in Table 5 indicate that the exchange rate feedback is fairly large, but the marginal likelihood does not provide support for this specification, compared to the benchmark model. Importantly, the estimates of the remaining model parameters change very little 30

Further, we add external habit formation in consumption to the estimated model, like in Adolfson, Laséen, Lindé, and Villani (2007) or Justiniano and Preston (2010). That is, the

\footnotetext{
${ }^{27}$ This exercise shows whether, if we restrict the estimation procedure in one dimension (here measurement error) where there is some discrepancy between the model and the data, first, the model can still explain the data, i.e. whether we obtain convergence in the mode maximization step, and second, whether estimation of the restricted model leads to reasonable estimates of the structural parameters and remaining shock variances.

${ }^{28}$ The exchange rate target is assumed to be consistent with steady state values.

${ }^{29} \mathrm{~A} \mathrm{U}(0,10)$ prior is applied similar to the prior for $\alpha_{\pi}$.

${ }^{30}$ Alternatively, we included a real exchange rate depreciation term $\left(q_{t+1}-q_{t}\right)$ in the Taylor rule with prior $\mathcal{N}\left(0.5,0.5^{2}\right)$ on its reaction coefficient. However, the reaction coefficient was not identified by the estimation. Moreover, we included the output gap (in deviations from steady state output) with prior $\mathcal{N}\left(0.5,0.5^{2}\right)$ on its reaction coefficient into the Taylor rule. The estimated reaction coefficient is close to zero (0.03). All other parameter values and the marginal likelihood remain virtually unchanged.
} 
Table 5: Sensitivity of parameter estimates. ${ }^{\mathrm{a}}$

\begin{tabular}{|c|c|c|c|c|c|c|c|}
\hline Parameter & Definition & Prior $^{b}$ & $\begin{array}{c}\text { Benchmark } \\
\text { model }\end{array}$ & $\begin{array}{l}\text { Smaller } \\
\text { meas. error }\end{array}$ & $\begin{array}{c}\text { Taylor } \\
\text { exch. rate }\end{array}$ & $\begin{array}{c}\text { Habit } \\
\text { formation }\end{array}$ & $\begin{array}{c}\text { Smaller } \\
\text { debt shocks }\end{array}$ \\
\hline$\sigma$ & Inv. elast. of intertemp. subst. & $\mathrm{U}(0,20)$ & 0.59 & 0.43 & 0.58 & 1.24 & 1.33 \\
\hline$h$ & Degree of habit formation & $\mathrm{U}(0,1)$ & - & - & - & 0.58 & - \\
\hline$\phi$ & Calvo price stickiness & $\mathrm{U}(0,1)$ & 0.19 & 0.14 & 0.19 & 0.54 & 0.64 \\
\hline$\vartheta$ & Degree of openness & $\mathrm{U}(0,1)$ & 0.42 & 0.57 & 0.42 & 0.14 & 0.12 \\
\hline$\alpha_{\pi}$ & Taylor rule inflation response & $\mathrm{U}(0,10)$ & 2.10 & 2.13 & 2.12 & 1.80 & 1.58 \\
\hline$\alpha_{q}$ & Taylor rule ex. rate response & $\mathrm{U}(0,10)$ & - & - & 0.24 & - & - \\
\hline$\kappa$ & Tax rule debt response & $\mathrm{U}\left(\kappa_{L}, 10\right)^{\mathrm{e}}$ & 0.53 & 0.53 & 0.53 & 0.42 & 0.41 \\
\hline$\Phi$ & Default elasticity & $\mathrm{U}(0,10)$ & 0.25 & 0.24 & 0.25 & 0.19 & 0.18 \\
\hline$\rho_{a}$ & $\mathrm{AR}(1)$ technology & $\mathrm{U}(0,1)$ & 0.91 & 0.91 & 0.91 & 0.95 & 0.97 \\
\hline$\rho_{g}$ & AR(1) gov. consumption & $\mathrm{U}(0,1)$ & 0.50 & 0.51 & 0.50 & 0.42 & 0.28 \\
\hline$\rho_{f}$ & $\mathrm{AR}(1)$ foreign debt ratio & $\mathrm{U}(0,1)$ & 0.86 & 0.86 & 0.86 & 0.90 & 0.93 \\
\hline$\sigma_{a}$ & Std. dev. technology shocks & $\mathrm{IG}(0.05, \infty)$ & 0.02 & 0.02 & 0.02 & 0.04 & 0.05 \\
\hline$\sigma_{g}$ & Std. dev. gov. consumption shocks & $\operatorname{IG}(0.05, \infty)$ & 0.04 & 0.04 & 0.04 & 0.04 & 0.04 \\
\hline$\sigma_{f}$ & Std. dev. foreign debt ratio shocks & $\operatorname{IG}(0.05, \infty)$ & 0.31 & 0.32 & 0.31 & 0.26 & - \\
\hline$\sigma_{\tau}$ & Std. dev. fiscal policy shocks & $\operatorname{IG}(0.05, \infty)$ & 0.10 & 0.11 & 0.10 & 0.08 & 0.07 \\
\hline$\sigma_{R}$ & Std. dev. interest rate shocks & $\operatorname{IG}(0.05, \infty)$ & 0.07 & 0.07 & 0.07 & 0.06 & 0.06 \\
\hline$\sigma_{c}$ & Std. dev. demand shocks & $\mathrm{IG}(0.05, \infty)$ & 0.02 & 0.01 & 0.02 & 0.09 & 0.05 \\
\hline$\sigma_{q}$ & Std. dev. meas. error on $\mathrm{REER}_{t}$ & $\mathrm{IG}(0.05, \infty)$ & 0.09 & - & 0.09 & 0.11 & 0.11 \\
\hline $\log p\left(Y^{T} \mid M_{i}\right)$ & Log marginal data density ${ }^{f}$ & & 873.67 & 849.86 & 870.47 & 880.67 & 854.00 \\
\hline
\end{tabular}

a The estimation results are based on 500,000 accepted draws from the RWM sampler, dropping the first 250,000 draws.

${ }^{\mathrm{b}} \mathrm{U}(a, b)$ refers to the continuous uniform distribution with lower bound $a$ and upper bound $b$; $\operatorname{IG}(c, d)$ refers to the inverse gamma distribution with mean $c$ and std. deviation $d$.

${ }^{c}$ For the specification with smaller measurement errors, the standard deviation $\sigma_{q}$ is calibrated to 0.05 .

${ }^{\mathrm{d}}$ For the specification with smaller debt shocks, the standard deviation $\sigma_{f}$ is calibrated to 0.15

e The lower bound is $\kappa_{L}=1-\beta\left(1-\bar{\delta}\right.$ ), which ensures that steady state domestic debt $b_{H} / \pi$ is positive such that $\Phi>0$ (see Appendix C).

f The marginal data density is estimated using Geweke's (1999) modified harmonic mean estimator. 
(domestic and foreign) households' preferences are modified accordingly:

$$
E_{0} \sum_{t=0}^{\infty} \beta^{t}\left(\exp \left(\varepsilon_{c, t}\right) \frac{\left(c_{t}-h \breve{c}_{t-1}\right)^{1-\sigma}}{1-\sigma}-\frac{n_{t}^{1+\eta}}{1+\eta}\right)
$$

where $h \in(0,1)$ and $\breve{c}_{t-1}$ denotes aggregate domestic consumption, which is taken as exogenous by the individual households 31 The first-order conditions for (domestic and foreign) consumption become

$$
\begin{aligned}
\lambda_{t} & =\exp \left(\varepsilon_{c, t}\right)\left(c_{t}-h c_{t-1}\right)^{-\sigma} \\
\lambda_{t}^{*} & =\left(c_{t}^{*}-h c_{t-1}^{*}\right)^{-\sigma}
\end{aligned}
$$

where the equilibrium conditions $c_{t}=\breve{c}_{t}$ and $c_{t}^{*}=\breve{c}_{t}^{*}$ have been imposed for all $t$. The introduction of habit formation is motivated by the idea that, if this is a salient feature of the data (see, for example, Adolfson, Laséen, Lindé, and Villani, 2007; Smets and Wouters, 2007; Justiniano and Preston, 2010), the associated modification of the consumption Euler equation may alter the importance of sovereign risk in explaining macroeconomic dynamics as well. The estimation results in Table 5 show that, although $h$ is fairly large with an estimated value of 0.58 and the marginal data density improves by $7 \log$ points, the estimated default elasticity and the policy coefficients remain sufficiently close to the baseline estimates 32 The default elasticity drops from 0.25 to 0.19 .

Next, the largest estimated standard deviation (of the debt issuance shock) $\sigma_{f}$ is calibrated to 0.15 , i.e. half of the benchmark estimate. This shock only has an impact on the division among domestic and foreign debt, but no effect on the real variables and the estimated default rate (see Table 4). With a smaller value of its standard deviation the model is restricted to explain more variation in domestic debt by the remaining structural shocks via cross-equation restrictions. The estimated persistence of government consumption decreases and there are also some significant changes in the remaining estimates compared to the benchmark case (notably $\sigma, \phi, \vartheta$ and $\alpha_{\pi}$ ). Most importantly, however, the estimated default elasticity of 0.18 still indicates a highly debt-elastic default rate.

We have also attempted to estimate the benchmark model by constrained maximum likelihood (ML), where we restricted the model parameters on their theoretically feasible range according to the domains in Table 1. It turned out that ML estimation was only feasible

\footnotetext{
${ }^{31} \mathrm{~A} \mathrm{U}(0,1)$ prior is elicited on $h$ consistent with its theoretical domain.

${ }^{32}$ We have not introduced habit formation in the basic model without sovereign risk since we here faced convergence problems in the mode optimization step.
} 


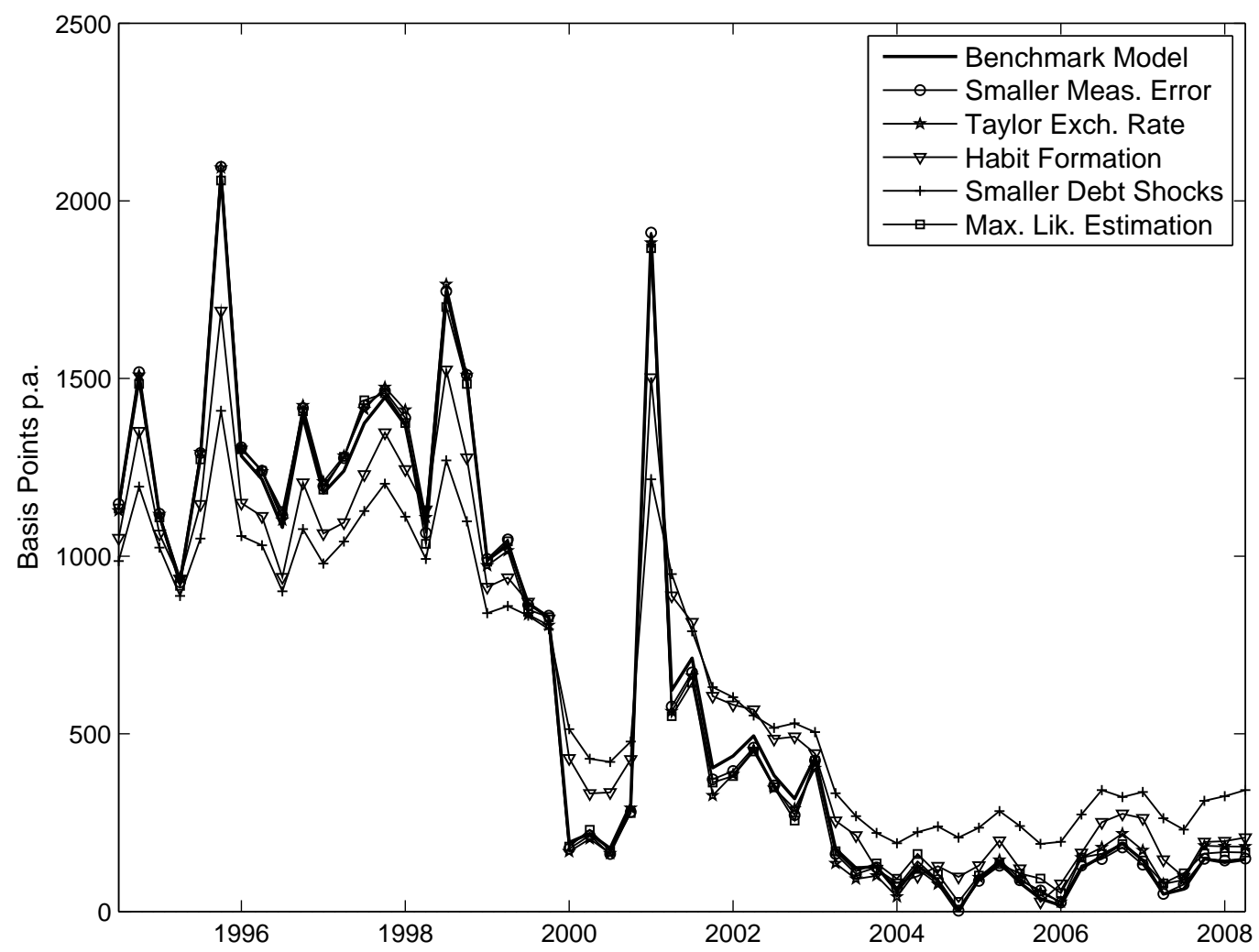

Figure 11: Estimated expected default rate $\left(E_{t} \tilde{\delta}_{t+1}\right)$ according to alternative models. Notes. The default rate is the estimate implied by the Kalman smoother at the posterior mean.

(in terms of convergence of the optimizer) when we calibrated the degree of price stickiness $\phi$ to its benchmark value of 0.19 . The estimation results for the remaining parameters show that only $\sigma$ and $\vartheta$ change significantly to 0.26 and 0.74 , respectively, whereas the other parameters remain close to the benchmark values. Again, the default elasticity is estimated to be highly debt-elastic (with a value of 0.23 ).

Finally, the estimated expected default rates from all estimated versions of the model are compared in Figure 11. The results are very similar across models, the only exceptions being the models with habit formation and smaller debt issuance shocks for which the default rate is somewhat less volatile, smaller during the first half of the sample and larger during the second half. However, even in those two cases the estimated default rate remains close to the estimate from the benchmark model. Setting the discount factor $\beta$ to alternative values of 0.97 and 0.999 leaves all the estimation results virtually unchanged. The standard deviation of the model-implied default premium is only affected at the third significant digit when changing $\beta$ while the correlation with the default premium for $\beta=0.99$ is one in both cases. 


\section{Conclusions}

We set up a mostly standard dynamic stochastic general equilibrium model of a small open economy where rigidities in domestic producer prices are the only nominal friction. A perceived possibility of sovereign debt default implies a time-varying default premium on government bonds which depends on the stock of real total debt and which we include into this otherwise standard NOEM model. We outline two main variants of the model which differ only with respect to the inclusion of the expected default rate. More specifically, the model without sovereign risk is a special case of the general model with sovereign risk where the parameter on the expected default rate in the Euler equation for government bonds is restricted to equal zero.

Using Bayesian estimation methods we find that the estimated expected default rate is highly debt-elastic and depends on fiscal policy, indicating that default fears are a relevant concern. Model comparisons clearly support the model with expected default rate as compared the standard New Keynesian small open economy model where the level of debt is irrelevant for the dynamics of nominal variables. We find that in the latter, large shocks are required in order to reconcile the observed dynamics of the nominal interest rate, the real exchange rate, government debt and aggregate demand. Accounting for sovereign risk leads to stronger internal propagation and better forecasting performance. In terms of policy implications, counterfactual experiments show that solid fiscal policy leads to less volatile debt and inflation dynamics, by reducing expected default rates. On the other hand, more active monetary policy is also an effective stabilization device for inflation and debt, but it does not reduce expected default rates.

Finally, there is empirical evidence that the relationship between government debt and default premia may contain non-linear elements (see, for example, Bayoumi, Goldstein, and Woglom, 1995) such that the linear estimation approach followed in this paper provides only an incomplete picture of this relationship. However, non-linear estimation methods are still not readily available. They might become a viable avenue in future research. Moreover, the linear model seems to provide a reasonable description of expected default rates (see the EMBIG Turkey spread in Figure 2). 


\section{References}

Abuaf, N., And P. Jorion (1996): "Purchasing Power Parity in the Long Run," Journal of Finance, $45,157-174$.

Adolfson, M., S. Laséen, J. Lindé, And M. Villani (2007): "Bayesian estimation of an open economy DSGE model with incomplete pass-through," Journal of International Economics, 72, $481-511$.

Aguiar, M., And G. Gopinath (2007): "Emerging Market Business Cycles: The Cycle Is the Trend," Journal of Political Economy, 115, 69-102.

Aktas, Z., N. Kaya, and U. Ozlale (2005): "The Prize Puzzle in Emerging Markets: Evidence from the Turkish Economy Using "Model Based" Risk Premium Derived from Domestic Fundamentals," Central Bank of Turkey Working Paper No. 05/02.

An, S., ANd F. Schorfheide (2007): "Bayesian Analysis of DSGE Models," Econometric Reviews, $26,113-172$.

Arellano, C. (2008): "Default Risk and Income Fluctuations in Emerging Economies," The American Economic Review, 98, 690-712.

Basci, E., ANd M. F. Ekinci (2005): "Bond Premium in Turkey.," Emerging Markets Finance and Trade, 41(2), $25-40$.

Bayoumi, T., M. Goldstein, and G. Woglom (1995): "Do Credit Markets Discipline Sovereign Borrowers? Evidence from the U.S. States," Journal of Money, Credit and Banking, 27(4), 1046-59.

Blanchard, O. J. (2005): "Fiscal Dominance and Inflation Targeting: Lessons from Brazil," in Inflation Targeting, Debt and the Brazilian experience 1999 to 2003, ed. by F. Giavazzi, I. Goldfajn, and S. Herrera. MIT Press.

Bohn, H. (1992): "Endogenous Government Spending and Ricardian Equivalence," Economic Journal, 102, 588-597.

Brooks, S., And A. Gelman (1998): "General methods for monitoring convergence of iterative simulations," Journal of Computational and Graphical Statistics, 7, 434-456.

Brulhart, M., and F. Trionfetti (2004): "Public expenditure, international specialisation and agglomeration," European Economic Review, 48, 851-881.

Budina, N., And S. J. G. van Wijnbergen (2008): "Quantitative Approaches to Fiscal Sustainability Analysis: A Case Study of Turkey since the Crisis of 2001," World Bank Economic Review, 23, 119-140.

Calvo, G. A. (1983): "Staggered prices in a utility-maximizing framework," Journal of Monetary Economics, 12(3), 383 - 398. 
Cantor, R. M., And F. Packer (1996): "Determinants and Impact of Sovereign Credit Ratings," Economic Policy Review, pp. 37-53.

Chang, R., And A. Fernández (2010): "On the Sources of Aggregate Fluctuations in Emerging Economies," Nber working papers, National Bureau of Economic Research, Inc.

Christoffel, K., G. Coenen, and A. Warne (2008): "The New Area-Wide Model of the Euro Area: A Micro-Founded Open-Economy Model for Policy Analysis and Forecasting," ECB Working Paper No. 944.

Eaton, J., And M. Gersovitz (1981): "Debt with Potential Repudiation: Theoretical and Empirical Analysis," The Review of Economic Studies, 48, 289-309.

EDwARDS, S. (1994): "LDC Foreign Borrowing and Default Risk: An Empirical Investigation," American Economic Review, 74, 726-734.

Eichengreen, B., And R. Hausmann (1999): "Exchange rates and financial fragility," in Proceedings of the Federal Reserve Bank of Kansas City: New Challenges for Monetary Policy, pp. $329-368$.

Eichengreen, B., R. Hausmann, And U. Panizza (2007): "Currency Mismatches, Debt Intolerance, and the Original Sin: Why They Are Not the Same and Why It Matters," in Capital Controls and Capital Flows in Emerging Economies: Policies, Practices and Consequences, NBER Chapters No. 0150 , pp. 121-170.

Eichengreen, B., And A. Mody (1998): "What Explains Changing Spreads on Emerging-Market Debt: Fundamentals or Market Sentiment?," NBER Working Paper No. 6408.

Ersel, H., and F. Ozatay (2008): "Fiscal Dominance and Inflation Targeting: Lessons from Turkey," Emerging Markets Finance and Trade, 44, 38-51.

Fagan, G., J. Henry, and R. Mestre (2005): "An area-wide model for the euro area," Economic Modelling, 22, 39-59.

Ferucci, G. (2003): "Empirical Determinants of Emerging Market Economies' Sovereign Bond Spreads," Bank of England Working Paper No. 205.

Galí, J., and T. Monacelli (2005): "Monetary Policy and Exchange Rate Volatility in a Small Open Economy," Review of Economic Studies, 72, 707-734.

GeweKe, J. F. (1999): "Using Simulation Methods for Bayesian Econometric Models: Inference, Developments and Communication," Econometric Reviews, 18, 1-126.

Gormez, Y., And G. Yilmaz (2007): "The Evolution of Exchange Rate Regime Choices in Turkey," in Proceedings of OeNB Workshops No. 13: The Experience of Exchange Rate Regimes in Southeastern Europe in a Historical and Comparative Perspective, Second Conference of the South-Eastern European Monetary History Network (SEEMHN). 
Justiniano, A., And B. Preston (2008): "Monetary Policy and Uncertainty in an Empirical Small Open Economy Model," Journal of Applied Econometrics, forthcoming.

(2010): "Can structural small open-economy models account for the influence of foreign disturbances?," Journal of International Economics, 81(1), 61 - 74.

Loyo, E. (2005): "Comment on Blanchard's "Fiscal Dominance and Inflation Targeting: Lessons from Brazil"," in Inflation Targeting, Debt and the Brazilian experience 1999 to 2003, ed. by F. Giavazzi, I. Goldfajn, and S. Herrera. MIT Press.

Lubik, T. A., And F. Schorfheide (2005): "A Bayesian Look at New Open Economy Macroeconomics," John Hopkins University Working Paper No. 521.

- (2007): "Do central banks respond to exchange rate movements? A structural investigation," Journal of Monetary Economics, 54, 1069-1087.

Min, H. G. (1998): "Determinants of Emerging Market Bond Spreads: Do Economic Fundamentals Matter?," World Bank Policy Research Working Paper No. 1899.

Neumeyer, P. A., And F. Perri (2005): "Business cycles in emerging economies: the role of interest rates," Journal of Monetary Economics, 52(2), 345 - 380.

Rogoff, K. (1996): "The Purchasing Power Parity Puzzle," Journal of Economic Literature, 34, $647-668$.

Schabert, A., And S. J. G. van Wijnbergen (2006): "Debt, Deficits, and Destabilizing Monetary Policy in Open Economies," Tinbergen Institute Discussion Paper No. 2006-045/2.

_ (2010): "Sovereign default and the stability of inflation targeting regimes," mimeo, University of Amsterdam.

Schmitt-Grohé, S., And M. Uribe (2007): "Optimal simple and implementable monetary and fiscal policy rules," Journal of Monetary Economics, 54, 1702-1725.

Smets, F., And R. Wouters (2007): "Shocks and Frictions in US Business Cycles: A Bayesian DSGE Approach," American Economic Review, 97, 586-606.

Trionfetti, F. (2000): "Discriminatory Public Procurement and International Trade," The World Economy, 23, 57-76.

URIBE, M., AND V. Z. Yue (2006): "Country spreads and emerging countries: Who drives whom?," Journal of International Economics, 69, 6-36.

Yazgan, M. E., And H. Yilmazkuday (2007): "Monetary Policy rules in practice: evidence from Turkey and Israel," Applied Financial Economics, 17, 1-8.

Yun, T. (1996): "Nominal Price Rigidity, Money Supply Endogeneity, and Business Cycles," Journal of Monetary Economics, 37, 345-370. 


\section{A Data Definitions}

This appendix provides details on data definitions, data sources and the construction of the foreign variables. All data are seasonally adjusted and the consumer price index is used to construct real variables with base year 1998, if they are only available in nominal terms from the original source. The domestic variable definitions and their sources are as follows:

- $\mathrm{GDP}_{t}$ : Real gross domestic product, Central Bank of the Republic of Turkey.

- $\mathrm{CONS}_{t}$ : Real private consumption expenditure, Central Bank of the Republic of Turkey.

- $\mathrm{GOV}_{t}$ : Real government consumption expenditure, Central Bank of the Republic of Turkey.

- $\mathrm{DEBT}_{t}$ : Domestic debt position of the treasury, Central Bank of the Republic of Turkey.

- $\mathrm{INT}_{t}$ : Annual net interest rate for 3-month treasury bills, constructed from data obtained from the Central Bank of the Republic of Turkey; if 3-month bills were not issued in some quarter, we use the closest maturity available.

- $\mathrm{INF}_{t}$ : Annualized rate of change of the quarterly CPI, State Institute of Statistics Turkey.

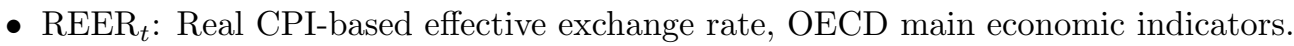

The foreign variables are constructed from euro area real private consumption and the annual inflation rate according to the Harmonized Index of Consumer Prices obtained from the Area-Wide Model database (Fagan, Henry, and Mestre, 2005), and real U.S. personal consumption and the CPIbased U.S. inflation rate (all urban sample, all items) obtained from the U.S. Bureau of Economic Analysis. Aggregate foreign consumption $\mathrm{CONS}_{t}^{*}$ and foreign inflation $\mathrm{INF}_{t}^{*}$ are computed according to the trade weights in the basket targeted by the Turkish central bank during the exchange rate targeting period (see Gormez and Yilmaz, 2007). That is, the euro area obtains a weight of 0.77 and the U.S. obtains a weight of 1 .

\section{B Steady State Properties}

In this appendix we derive a partial solution for the non-stochastic steady state of the model, which is sufficient for its implementation. We take as given the steady state interest rate $R_{H}=\bar{R}_{H}$, steady state marginal costs $m c=\overline{m c}$, the average foreign inflation CPI rate $\bar{\pi}^{*}$, the average domestic CPI inflation rate $\pi=\bar{\pi}$, and the shares $s_{c}=\bar{s}_{c}$ and $s_{g}=\bar{s}_{g}$. Furthermore, the steady state is assumed to satisfy the purchasing power parity (PPP) condition, i.e. the steady state real exchange rate equals unity $(q=1)$. While usually not taken seriously as a short-term proposition, empirical evidence supports the usefulness of PPP as a long-run anchor for real exchange rates (Rogoff, 1996) 33 In order to obtain a well-defined equilibrium, we set the values of $\bar{\delta}, \overline{m c}, \bar{\pi}^{*}, \bar{\pi}_{X}, \bar{c}^{*}, \bar{g}$ and $\xi$ accordingly, as follows.

First, the process for productivity implies that

$$
\left(1-\rho_{a}\right) \log a=0
$$

\footnotetext{
${ }^{33}$ In particular, the estimated half-life of deviations from PPP in OECD countries is about three years (see Abuaf and Jorion, 1996).
} 
or $a=1$. Similarly, the remaining stochastic processes imply that $g=\bar{g}$ and $f=\bar{f}$. The foreign VAR process implies that

$$
\left(I-\Phi_{1 *}-\Phi_{2 *}-\Phi_{3 *}-\Phi_{4 *}\right)\left[\begin{array}{c}
\log c^{*} \\
\log \pi^{*}
\end{array}\right]=\left(I-\Phi_{1 *}-\Phi_{2 *}-\Phi_{3 *}-\Phi_{4 *}\right)\left[\begin{array}{c}
\log \bar{c}^{*} \\
\log \bar{\pi}^{*}
\end{array}\right]
$$

and therefore, assuming stability of the VAR such that $\left(I-\Phi_{1 *}-\Phi_{2 *}-\Phi_{3 *}-\Phi_{4 *}\right)$ is non-singular, $c^{*}=\bar{c}^{*}$ and $\pi^{*}=\bar{\pi}^{*}$ can be taken as given.

Second, the central bank is assumed to achieve its target rate of nominal depreciation in the steady state, i.e.

$$
\pi_{X}=\bar{\pi}_{X}=\pi / \bar{\pi}^{*}
$$

Therefore, we can take $\pi=\bar{\pi}=\bar{\pi}_{X} \bar{\pi}^{*}$ as given.

Third, the steady state interest rate satisfies

$$
R_{H}=\bar{R}_{H}=\frac{\bar{\pi}}{\beta(1-\bar{\delta})}
$$

such that $\bar{\delta}$ is given by

$$
\bar{\delta}=1-\frac{\bar{\pi} / \bar{R}_{H}}{\beta}<1
$$

Fourth, the intermediate goods firms' first-order conditions for price setting imply that

$$
m c=\frac{\epsilon-1}{\epsilon}
$$

so we can take $m c=\overline{m c}$ as given by calibrating $\epsilon$ accordingly.

Fifth, we set the constant $\xi$ (which depends on initial endowments) such that $q=1$. In order to see this, notice that the international risk sharing condition yields

$$
\lambda^{*}=\xi q \lambda
$$

or, substituting out $\lambda^{*}=\bar{c}^{*-\sigma}$ and $\lambda=c^{-\sigma}$ and solving for $q$ :

$$
q=\frac{1}{\xi}\left(\frac{c}{\bar{c}^{*}}\right)^{\sigma}
$$

In order to obtain an expression for the steady state real exchange rate in terms of the given values for $s_{c}$ and $s_{g}$, solve the market clearing equation in steady state for $s_{c^{*}}$ :

$$
y_{H}=(1-\vartheta) q^{\frac{\vartheta}{1-\vartheta}} c+\vartheta^{*} q^{\frac{1}{1-\vartheta}} c^{*}+g
$$

or

$$
s_{c^{*}}=\frac{1-(1-\vartheta) q^{\frac{\vartheta}{1-\vartheta}} \bar{s}_{c}-\bar{s}_{g}}{q^{\frac{1}{1-\vartheta}} \vartheta^{*}} .
$$

Therefore, we have

$$
q=\frac{1}{\xi}\left(\frac{\bar{s}_{c}}{s_{c^{*}}}\right)^{\sigma}=\frac{1}{\xi}\left(\frac{q^{\frac{1}{1-\vartheta}} \vartheta^{*} \bar{s}_{c}}{1-(1-\vartheta) q^{\frac{\vartheta}{1-\vartheta}} \bar{s}_{c}-\bar{s}_{g}}\right)^{\sigma}
$$


In order to fix $q=1$, we can set the constant $\xi$ accordingly:

$$
\xi=\left(\frac{\vartheta^{*} \bar{s}_{c}}{1-(1-\vartheta) \bar{s}_{c}-\bar{s}_{g}}\right)^{\sigma}
$$

Finally, we need to fix values $\bar{c}^{*}$ and $\bar{g}$ in order to match $s_{c}=\bar{s}_{c}$ and $s_{g}=\bar{s}_{g}$. For $q=1$ it follows from the international risk sharing condition that

$$
c=\xi^{1 / \sigma} c^{*}=\xi^{1 / \sigma} \bar{c}^{*}
$$

Furthermore, the steady state real wage rate is equal to steady state marginal costs,

$$
w=\overline{m c} .
$$

Then the domestic households' first-order condition for labor supply implies that

$$
c^{\sigma} n^{\eta}=w=\overline{m c}
$$

or

$$
y_{H}=\left(\frac{\overline{m c}}{c^{\sigma}}\right)^{1 / \eta}=\left(\frac{\overline{m c} / \xi}{\bar{c}^{* \sigma}}\right)^{1 / \eta}
$$

since $y_{H}=n$ in the steady state. We then obtain the desired values for $\bar{c}^{*}$ and $\bar{g}$ from

$$
\bar{c}^{*}=c^{*}=s_{c^{*}} y_{H}=s_{c^{*}}\left(\frac{\overline{m c} / \xi}{\bar{c}^{* \sigma}}\right)^{1 / \eta}
$$

or

$$
\bar{c}^{*}=(\overline{m c} / \xi)^{\frac{1 / \sigma}{\eta / \sigma+1}}\left(\frac{1-(1-\vartheta) \bar{s}_{c}-\bar{s}_{g}}{\vartheta^{*}}\right)^{\frac{\eta / \sigma}{\eta / \sigma+1}}
$$

and

$$
\bar{g}=g=s_{g} y_{H}=\bar{s}_{g}\left(\frac{\overline{m c} / \xi}{\bar{c}^{* \sigma}}\right)^{1 / \eta}
$$

or

$$
\bar{g}=\frac{\bar{s}_{g}(\overline{m c} / \xi)^{\frac{1 / \sigma}{\eta / \sigma+1}}}{\left(\frac{1-(1-\vartheta) \bar{s}_{c}-\bar{s}_{g}}{\vartheta^{*}}\right)^{\frac{1}{\eta / \sigma+1}}} .
$$

In the implementation of the model, we need to verify that $\bar{c}^{*}>0$ and $\bar{g}>0$.

In addition, we derive some steady state expressions which are used in the log-linearization step below. The debt issuance rule implies that (since $f=\bar{f})$ :

$$
\frac{b_{F}}{R_{F}}=\bar{f} \frac{b_{H}}{R_{H}}
$$

or

$$
\frac{b_{F}}{\pi^{*}}=\bar{f} \frac{b_{H}}{\pi} .
$$

where we have used the domestic and foreign households' consumption Euler equations in steady state:

$$
R_{H}=\frac{\pi}{\beta(1-\delta)}, \quad R_{F}=\frac{\pi^{*}}{\beta(1-\delta)}
$$


Furthermore, steady state total debt is defined by

$$
b=b_{H} / \pi+b_{F} / \pi^{*}
$$

\section{Log-Linearization}

In this appendix we log-linearize the equilibrium conditions around the non-stochastic steady state. In a neighborhood of the steady state, the rational expectations solution of the model is then approximated by the solution of the linearized system.

1. First-order condition for domestic consumption:

$$
\lambda_{t}=\exp \left(\varepsilon_{c, t}\right) c_{t}^{-\sigma}
$$

Taking logs and subtracting steady state values yields the log-linearized version:

$$
\begin{aligned}
\log \lambda_{t} & =\varepsilon_{c, t}-\sigma \log c_{t} \\
\log \lambda_{t}-\log \lambda & =\varepsilon_{c, t}-\sigma\left(\log c_{t}-\log c\right) \\
\hat{\lambda}_{t} & =\varepsilon_{c, t}-\sigma \hat{c}_{t} .
\end{aligned}
$$

2. First-order condition for labor supply:

$$
n_{t}^{\eta}=\lambda_{t} w_{t}
$$

Similarly as above, taking logs and subtracting steady state values yields the log-linearized version:

$$
\eta \hat{n}_{t}=\hat{\lambda}_{t}+\hat{w}_{t}
$$

3. First-order condition for foreign consumption:

$$
\lambda_{t}^{*}=c_{t}^{*-\sigma}
$$

The log-linearized version is

$$
\hat{\lambda}_{t}^{*}=-\sigma \hat{c}_{t}^{*}
$$

4. Domestic production:

$$
y_{H, t} v_{t}=a_{t} n_{t} .
$$

It can be shown that, in a neighborhood of the steady state, the price dispersion term $v_{t}=$ $\int_{0}^{1}\left(\frac{P_{H, t}^{i}}{P_{t}}\right)^{-\epsilon} d i$ is equal to zero up to a first-order approximation (Yun, 1996), i.e. $\hat{v}_{t}=0$. Log-linearizing thus yields

$$
\hat{y}_{H, t}=\hat{a}_{t}+\hat{n}_{t} .
$$

5. Labor demand function:

$$
w_{t}=\frac{P_{H, t}}{P_{t}} m c_{t} a_{t}
$$


Since $P_{H, t} / P_{t}=q_{t}^{\frac{\vartheta}{\vartheta-1}}$, the log-linearized version is

$$
\widehat{m c}_{t}=\frac{\vartheta}{1-\vartheta} \hat{q}_{t}+\hat{w}_{t}-\hat{a}_{t}
$$

6. Domestic inflation:

Following (Yun, 1996), log-linearizing the intermediate goods producers' first-order condition for pricing yields the open economy Phillips curve

$$
\hat{\pi}_{H, t}=\frac{(1-\phi)(1-\phi \beta)}{\phi} \widehat{m c}_{t}+\beta E_{t} \hat{\pi}_{H, t+1}
$$

7. CPI inflation:

$$
\pi_{t}=\pi_{H, t}\left(q_{t} / q_{t-1}\right)^{\frac{\vartheta}{1-\vartheta}} .
$$

The log-linearized version is

$$
\hat{\pi}_{t}=\hat{\pi}_{H, t}+\frac{\vartheta}{1-\vartheta}\left(\hat{q}_{t}-\hat{q}_{t-1}\right) .
$$

8. International risk sharing:

$$
\lambda_{t}^{*}=\xi q_{t} \lambda_{t}
$$

where $\xi$ is a constant which depends on initial endowments. Taking logs and subtracting steady state values yields

$$
\hat{\lambda}_{t}^{*}=\hat{q}_{t}+\hat{\lambda}_{t}
$$

9. Taylor rule:

$$
\frac{R_{H, t}}{R_{H}}=\left(\frac{\pi_{t}}{\pi}\right)^{\alpha_{\pi}} \exp \left(\varepsilon_{R, t}\right)
$$

Taking logs yields the log-linearized version

$$
\hat{R}_{H, t}=\alpha_{\pi} \hat{\pi}_{t}+\varepsilon_{R, t} .
$$

10. Market clearing:

$$
y_{H, t}=(1-\vartheta) q_{t}^{\frac{\vartheta}{1-\vartheta}} c_{t}+\vartheta^{*} q_{t}^{\frac{1}{1-\vartheta}} c_{t}^{*}+g_{t}
$$

The market clearing condition can be log-linearized as follows:

$$
\begin{aligned}
y_{H} \hat{y}_{H, t} & =(1-\vartheta) c\left(\frac{\vartheta}{1-\vartheta} \hat{q}_{t}+\hat{c}_{t}\right)+\vartheta^{*} c^{*}\left(\frac{1}{1-\vartheta} \hat{q}_{t}+\hat{c}_{t}^{*}\right)+g \hat{g}_{t} \\
& =(1-\vartheta) c \hat{c}_{t}+\vartheta^{*} c^{*} \hat{c}_{t}^{*}+\left(\vartheta c+\frac{\vartheta^{*}}{1-\vartheta} c^{*}\right) \hat{q}_{t}+g \hat{g}_{t}
\end{aligned}
$$

or

$$
\hat{y}_{H, t}=(1-\vartheta) s_{c} \hat{c}_{t}+\vartheta^{*} s_{c^{*}} \hat{c}_{t}^{*}+\left(\vartheta s_{c}+\frac{\vartheta^{*}}{1-\vartheta} s_{c^{*}}\right) \hat{q}_{t}+s_{g} \hat{g}_{t} .
$$

where $s_{c}=c / y_{H}, s_{g}=g / y_{H}$ and $s_{c^{*}}=c^{*} / y_{H}$ denote the shares of domestic consumption, government consumption and foreign consumption over domestic output. In steady state, we have (see Appendix B)

$$
s_{c^{*}}=\frac{1-(1-\vartheta) s_{c}-s_{g}}{\vartheta^{*}} .
$$


We take $s_{c}=\bar{s}_{c}$ and $s_{g}=\bar{s}_{g}$ as given so that

$$
\begin{aligned}
\hat{y}_{H, t}= & (1-\vartheta) \bar{s}_{c} \hat{c}_{t}+\left[1-(1-\vartheta) \bar{s}_{c}-\bar{s}_{g}\right] \hat{c}_{t}^{*} \\
& +\left(\vartheta \bar{s}_{c}+\frac{1-(1-\vartheta) \bar{s}_{c}-\bar{s}_{g}}{1-\vartheta}\right) \hat{q}_{t}+\bar{s}_{g} \hat{g}_{t} .
\end{aligned}
$$

11. Debt issuance

$$
X_{t} \frac{B_{F, t}}{R_{F, t}}=f_{t} \frac{B_{H, t}}{R_{H, t}}
$$

In real terms:

$$
q_{t} \frac{b_{F, t}}{R_{F, t}}=f_{t} \frac{b_{H, t}}{R_{H, t}}
$$

Taking logs and subtracting steady state values yields

$$
\hat{q}_{t}+\hat{b}_{F, t}-\hat{R}_{F, t}=\hat{f}_{t}+\hat{b}_{H, t}-\hat{R}_{H, t} .
$$

12. Total debt:

$$
\begin{aligned}
b_{t} & =\left(B_{H, t-1}+X_{t} B_{F, t-1}\right) / P_{t} \\
& =b_{H, t-1} \pi_{t}^{-1}+q_{t} b_{F, t-1} \pi_{t}^{*-1} .
\end{aligned}
$$

A first-order Taylor expansion around the steady state yields

$$
\begin{aligned}
b_{t}-b= & \frac{1}{\pi}\left(b_{H, t-1}-b_{H}\right)-\frac{b_{H}}{\pi^{2}}\left(\pi_{t}-\pi\right) \\
& +\frac{b_{F}}{\pi^{*}}\left(q_{t}-q\right)+\frac{1}{\pi^{*}}\left(b_{F, t-1}-b_{F}\right)-\frac{b_{F}}{\pi^{* 2}}\left(\pi_{t}^{*}-\pi^{*}\right)
\end{aligned}
$$

or

$$
b \hat{b}_{t}=\frac{b_{H}}{\pi}\left(\hat{b}_{H, t-1}-\hat{\pi}_{t}\right)+\frac{b_{F}}{\pi^{*}}\left(\hat{q}_{t}+\hat{b}_{F, t-1}-\hat{\pi}_{t}^{*}\right) .
$$

Using $b=b_{H} / \pi+b_{F} / \pi^{*}$ and $b_{F} / \pi^{*}=\bar{f}\left(b_{H} / \pi\right)$ (see Appendix [B]):

$$
(1+\bar{f}) \hat{b}_{t}=\hat{b}_{H, t-1}-\hat{\pi}_{t}+\bar{f}\left(\hat{q}_{t}+\hat{b}_{F, t-1}-\hat{\pi}_{t}^{*}\right) .
$$

13. Government budget:

$$
\frac{B_{H, t}}{R_{H, t}}+X_{t} \frac{B_{F, t}}{R_{F, t}}+P_{t} \tau_{t}=P_{H, t} g_{t}+B_{H, t-1}+X_{t} B_{F, t-1},
$$

where

$$
P_{t} \tau_{t}=\kappa\left(B_{H, t-1}+X_{t} B_{F, t-1}\right)+P_{t} \exp \left(\varepsilon_{\tau, t}\right) .
$$

In real terms:

$$
\begin{array}{r}
\frac{b_{H, t}}{R_{H, t}}+q_{t} \frac{b_{F, t}}{R_{F, t}}+\kappa \\
=\frac{\left.P_{H, t-1} \pi_{t}^{-1}+q_{t} b_{F, t-1} \pi_{t}^{*-1}\right)+\exp \left(\varepsilon_{\tau, t}\right)}{P_{t}} g_{t}+b_{H, t-1} \pi_{t}^{-1}+q_{t} b_{F, t-1} \pi_{t}^{*-1}
\end{array}
$$


or, substituting out $b_{t}=b_{H, t-1} \pi_{t}^{-1}+q_{t} b_{F, t-1} \pi_{t}^{*-1}$ and $P_{H, t} / P_{t}=q_{t}^{\frac{\vartheta}{\vartheta-1}}$ :

$$
\frac{b_{H, t}}{R_{H, t}}+q_{t} \frac{b_{F, t}}{R_{F, t}}=q_{t}^{\frac{\vartheta}{\vartheta-1}} g_{t}+(1-\kappa) b_{t}-\exp \left(\varepsilon_{\tau, t}\right)
$$

In steady state, we have

$$
\frac{b_{H}}{R_{H}}+\frac{b_{F}}{R_{F}}=g+(1-\kappa) b
$$

or, using $R_{H}=\frac{\pi}{\beta(1-\delta)}, R_{F}=\frac{\pi^{*}}{\beta(1-\delta)}, b=b_{H} / \pi+b_{F} / \pi^{*}$ and $b_{F} / \pi^{*}=\bar{f}\left(b_{H} / \pi\right)$ :

$$
\frac{b_{H}}{\pi}=\frac{g(1+\bar{f})^{-1}}{\kappa+\beta(1-\delta)-1} .
$$

The budget constraint can then be log-linearized as follows:

$$
\begin{aligned}
\frac{b_{H}}{R_{H}}\left(\hat{b}_{H, t}-\hat{R}_{H, t}\right) & +\frac{b_{F}}{R_{F}}\left(\hat{q}_{t}+\hat{b}_{F, t}-\hat{R}_{F, t}\right) \\
& =g\left(\hat{g}_{t}-\frac{\vartheta}{1-\vartheta} \hat{q}_{t}\right)+(1-\kappa) b \hat{b}_{t}-\varepsilon_{\tau, t}
\end{aligned}
$$

or, substituting out steady state values,

$$
\begin{aligned}
\frac{b_{H}}{\pi} \beta(1-\delta)\left[\hat{b}_{H, t}\right. & \left.-\hat{R}_{H, t}+\bar{f}\left(\hat{q}_{t}+\hat{b}_{F, t}-\hat{R}_{F, t}\right)\right] \\
& =g\left(\hat{g}_{t}-\frac{\vartheta}{1-\vartheta} \hat{q}_{t}\right)+\frac{b_{H}}{\pi}(1-\kappa)(1+\bar{f}) \hat{b}_{t}-\varepsilon_{\tau, t} .
\end{aligned}
$$

Dividing through by $\frac{b_{H}}{\pi} \beta(1-\delta)$ yields

$$
\begin{aligned}
\hat{b}_{H, t}-\hat{R}_{H, t}+\bar{f}\left(\hat{q}_{t}+\hat{b}_{F, t}-\hat{R}_{F, t}\right)-\frac{(1-\kappa)(1+\bar{f})}{\beta(1-\delta)} \hat{b}_{t} \\
=\frac{g}{\frac{b_{H}}{\pi} \beta(1-\delta)}\left(\hat{g}_{t}-\frac{\vartheta}{1-\vartheta} \hat{q}_{t}\right)-\frac{1}{\frac{b_{H}}{\pi} \beta(1-\delta)} \varepsilon_{\tau, t} .
\end{aligned}
$$

or, using $\frac{b_{H}}{\pi}=\frac{g(1+\bar{f})^{-1}}{\kappa+\beta(1-\delta)-1}$ and normalizing the fiscal policy shock $\varepsilon_{\tau, t}$ such that the normalized shock has variance $\sigma_{\tau}^{2}$ :

$$
\begin{aligned}
\hat{b}_{H, t}-\hat{R}_{H, t}+\bar{f}\left(\hat{q}_{t}+\hat{b}_{F, t}-\hat{R}_{F, t}\right)-\frac{(1-\kappa)(1+\bar{f})}{\beta(1-\bar{\delta})} \hat{b}_{t} \\
=\frac{\kappa+\beta(1-\bar{\delta})-1}{\beta(1-\bar{\delta})(1+\bar{f})^{-1}}\left(\hat{g}_{t}-\frac{\vartheta}{1-\vartheta} \hat{q}_{t}\right)-\varepsilon_{\tau, t} .
\end{aligned}
$$

Recall that we take $\delta=\bar{\delta}$ as given.

14. Domestic Euler equation:

$$
\lambda_{t}=R_{H, t} \beta E_{t}\left[\left(1-\delta_{t+1}\right) \lambda_{t+1} \pi_{t+1}^{-1}\right] .
$$

Defining $\Xi_{t}=1-\delta_{t}$, the log-linearized version is

$$
\hat{\lambda}_{t}=E_{t} \hat{\lambda}_{t+1}+\hat{R}_{H, t}-E_{t} \hat{\pi}_{t+1}+E_{t} \widehat{\Xi}_{t+1} .
$$

A first-order Taylor expansion of $\Xi_{t}$ at the steady state furthermore yields (where we use 
$\left.\frac{b_{F}}{\pi^{*}}=\bar{f} \frac{b_{H}}{\pi}\right):$

$$
\begin{aligned}
\Xi_{t} & =\Xi-\left(\left.\frac{\partial \delta_{t}(\cdot)}{\partial b_{t}}\right|_{b_{t}=b}\right)\left[\begin{array}{c}
\pi^{-1}\left(b_{H, t-1}-b_{H}\right)-b_{H} \pi^{-2}\left(\pi_{t}-\pi\right) \\
+\pi^{*-1}\left(b_{F, t-1}-b_{F}\right)+b_{F} \pi^{*-1}\left(q_{t}-1\right) \\
-b_{F} \pi^{*-2}\left(\pi_{t}^{*}-\pi^{*}\right)
\end{array}\right] \\
& =\Xi-\left(\left.\frac{\partial \delta_{t}(\cdot)}{\partial b_{t}}\right|_{b_{t}=b}\right)\left[\begin{array}{c}
b_{H} \pi^{-1} \hat{b}_{H, t-1}-b_{H} \pi^{-1} \hat{\pi}_{t} \\
+b_{F} \pi^{*-1} \hat{b}_{F, t-1}+b_{F} \pi^{*-1} \hat{q}_{t} \\
-b_{F} \pi^{*-1} \hat{\pi}_{t}^{*}
\end{array}\right] \\
& =\Xi-\left(\left.\frac{\partial \delta_{t}(\cdot)}{\partial b_{t}}\right|_{b_{t}=b}\right)\left(\frac{b_{H}}{\pi}\right)\left[\begin{array}{c}
\left.\hat{b}_{H, t-1}-\hat{\pi}_{t}+\bar{f}\left(\hat{q}_{t}+\hat{b}_{F, t-1}-\hat{\pi}_{t}^{*}\right)\right]
\end{array}\right.
\end{aligned}
$$

or, since $\Xi=1-\delta$ :

$$
\begin{aligned}
\widehat{\Xi}_{t} & =-\frac{b_{H} / \pi}{1-\delta}\left(\left.\frac{\partial \delta_{t}(\cdot)}{\partial b_{t}}\right|_{b_{t}=b}\right)\left[\hat{b}_{H, t-1}-\hat{\pi}_{t}+\bar{f}\left(\hat{q}_{t}+\hat{b}_{F, t-1}-\hat{\pi}_{t}^{*}\right)\right] \\
& =-\Phi\left[\hat{b}_{H, t-1}-\hat{\pi}_{t}+\bar{f}\left(\hat{q}_{t}+\hat{b}_{F, t-1}-\hat{\pi}_{t}^{*}\right)\right] \\
& =-\Phi(1+\bar{f}) \hat{b}_{t} .
\end{aligned}
$$

The log-linearized default probability is

$$
\delta \hat{\delta}_{t}=-\Xi \widehat{\Xi}_{t}=\Phi(1-\delta)(1+\hat{f}) \hat{b}_{t}
$$

or, in absolute deviations from steady state, taking $\delta=\bar{\delta}$ as given:

$$
\tilde{\delta}_{t}=\Phi(1-\bar{\delta})(1+\bar{f}) \hat{b}_{t} .
$$

Hence, we obtain the following log-linearized consumption Euler equation:

$$
\begin{aligned}
\hat{\lambda}_{t} & =E_{t} \hat{\lambda}_{t+1}+\hat{R}_{H, t}-E_{t} \hat{\pi}_{t+1}-\Phi(1+\bar{f}) E_{t} \hat{b}_{t+1} \\
& =E_{t} \hat{\lambda}_{t+1}+\hat{R}_{H, t}-E_{t} \hat{\pi}_{t+1}-\frac{1}{1-\bar{\delta}} E_{t} \tilde{\delta}_{t+1} .
\end{aligned}
$$

15. Foreign Euler equation:

$$
\lambda_{t}^{*}=R_{F, t} \beta E_{t}\left[\left(1-\delta_{t+1}\right) \lambda_{t+1}^{*} \pi_{t+1}^{*-1}\right] .
$$

Similarly as above, the log-linearized version is

$$
\hat{\lambda}_{t}^{*}=E_{t} \hat{\lambda}_{t+1}^{*}+\hat{R}_{F, t}-E_{t} \hat{\pi}_{t+1}^{*}-\frac{1}{1-\bar{\delta}} E_{t} \tilde{\delta}_{t+1} .
$$

16. Productivity shock:

$$
\log a_{t}=\rho_{a} \log a_{t-1}+\varepsilon_{a, t} .
$$

Since $a=1$, the log-linearized version is

$$
\begin{aligned}
\log a_{t}-\log a & =\rho_{a}\left(\log a_{t-1}-\log a\right)+\varepsilon_{a, t} \\
\hat{a}_{t} & =\rho_{a} \hat{a}_{t-1}+\varepsilon_{a, t} .
\end{aligned}
$$


17. Government goods purchases:

$$
\log \left(g_{t} / \bar{g}\right)=\rho_{g} \log \left(g_{t-1} / \bar{g}\right)+\varepsilon_{g, t}
$$

Since $g=\bar{g}$, the log-linearized version is

$$
\hat{g}_{t}=\rho_{g} \hat{g}_{t-1}+\varepsilon_{g, t}
$$

18. Foreign debt share:

$$
\log \left(f_{t} / \bar{f}\right)=\rho_{f} \log \left(f_{t-1} / \bar{f}\right)+\varepsilon_{f, t} .
$$

Since $f=\bar{f}$, the log-linearized version is

$$
\hat{f}_{t}=\rho_{f} \hat{f}_{t-1}+\varepsilon_{f, t} .
$$

19. Foreign variables:

$$
\begin{aligned}
{\left[\begin{array}{c}
\log c_{t}^{*} \\
\log \pi_{t}^{*}
\end{array}\right]=} & \left(I-\Phi_{1 *}-\Phi_{2 *}-\Phi_{3 *}-\Phi_{4 *}\right)\left[\begin{array}{c}
\log \bar{c}^{*} \\
\log \bar{\pi}^{*}
\end{array}\right]+\Phi_{1 *}\left[\begin{array}{c}
\log c_{t-1}^{*} \\
\log \pi_{t-1}^{*}
\end{array}\right] \\
& +\Phi_{2 *}\left[\begin{array}{c}
\log c_{t-2}^{*} \\
\log \pi_{t-2}^{*}
\end{array}\right]+\Phi_{3 *}\left[\begin{array}{c}
\log c_{t-3}^{*} \\
\log \pi_{t-3}^{*}
\end{array}\right]+\Phi_{4 *}\left[\begin{array}{c}
\log c_{t-4}^{*} \\
\log \pi_{t-4}^{*}
\end{array}\right]+\left[\begin{array}{c}
v_{c^{*}, t} \\
v_{\pi^{*}, t}^{*}
\end{array}\right]
\end{aligned}
$$

where

$$
\left[v_{c^{*}, t}, v_{\pi^{*}, t}\right]^{\prime} \sim N I D\left(0, \Sigma_{*}\right) .
$$

Since $c^{*}=\bar{c}^{*}$ and $\pi^{*}=\bar{\pi}^{*}$, the log-linearized version is

$$
\begin{aligned}
{\left[\begin{array}{c}
\hat{c}_{t}^{*} \\
\hat{\pi}_{t}^{*}
\end{array}\right]=} & \Phi_{1 *}\left[\begin{array}{c}
\hat{c}_{t-1}^{*} \\
\hat{\pi}_{t-1}^{*}
\end{array}\right]+\Phi_{2 *}\left[\begin{array}{c}
\hat{c}_{t-2}^{*} \\
\hat{\pi}_{t-2}^{*}
\end{array}\right] \\
& +\Phi_{3 *}\left[\begin{array}{c}
\hat{c}_{t-3}^{*} \\
\hat{\pi}_{t-3}^{*}
\end{array}\right]+\Phi_{4 *}\left[\begin{array}{c}
\hat{c}_{t-4}^{*} \\
\hat{\pi}_{t-4}^{*}
\end{array}\right]+\left[\begin{array}{c}
v_{c^{*}, t} \\
v_{\pi^{*}, t}^{*}
\end{array}\right] .
\end{aligned}
$$

Our identifying assumption is that foreign consumption affects foreign inflation within a quarter but not vice versa. Thus, we apply a recursive Cholesky identification scheme: $\Sigma_{*}=C_{*} C_{*}^{\prime}$, where $C_{*}$ is a non-singular lower triangular matrix. Then we can write the identified foreign VAR process as follows:

$$
\begin{aligned}
C_{*}^{-1}\left[\begin{array}{c}
\hat{c}_{t}^{*} \\
\hat{\pi}_{t}^{*}
\end{array}\right]= & C_{*}^{-1} \Phi_{1 *}\left[\begin{array}{c}
\hat{c}_{t-1}^{*} \\
\hat{\pi}_{t-1}^{*}
\end{array}\right]+C_{*}^{-1} \Phi_{2 *}\left[\begin{array}{c}
\hat{c}_{t-2}^{*} \\
\hat{\pi}_{t-2}^{*}
\end{array}\right] \\
& +C_{*}^{-1} \Phi_{3 *}\left[\begin{array}{c}
\hat{c}_{t-3}^{*} \\
\hat{\pi}_{t-3}^{*}
\end{array}\right]+C_{*}^{-1} \Phi_{4 *}\left[\begin{array}{c}
\hat{c}_{t-4}^{*} \\
\hat{\pi}_{t-4}^{*}
\end{array}\right]+\left[\begin{array}{c}
\varepsilon_{c^{*}, t} \\
\varepsilon_{\pi^{*}, t}
\end{array}\right]
\end{aligned}
$$

where

$$
\left[\varepsilon_{c^{*}, t}, \varepsilon_{\pi^{*}, t}\right]^{\prime} \sim N I D(0, I),
$$


or, in simultaneous equations form (since $C_{*}^{-1}$ is a lower triangular matrix):

$$
\begin{aligned}
\rho_{0 *}^{c c} \hat{c}_{t}^{*}= & \rho_{1 *}^{c c} \hat{c}_{t-1}^{*}+\rho_{1 *}^{c \pi} \hat{\pi}_{t-1}^{*}+\rho_{2 *}^{c c} \hat{c}_{t-2}^{*}+\rho_{2 *}^{c \pi} \hat{\pi}_{t-2}^{*} \\
& +\rho_{3 *}^{c c} \hat{c}_{t-3}^{*}+\rho_{3 *}^{c \pi} \hat{\pi}_{t-3}^{*}+\rho_{4 *}^{c c} \hat{c}_{t-4}^{*}+\rho_{4 *}^{c \pi} \hat{\pi}_{t-4}^{*}+\varepsilon_{c^{*}, t} \\
\rho_{0 *}^{\pi \pi} \hat{\pi}_{t}^{*}+\rho_{0 *}^{\pi c} \hat{c}_{t}^{*}= & \rho_{1 *}^{\pi \pi} \hat{\pi}_{t-1}^{*}+\rho_{1 *}^{\pi c} \hat{c}_{t-1}^{*}+\rho_{2 *}^{\pi \pi} \hat{\pi}_{t-2}^{*}+\rho_{2 *}^{\pi c} \hat{c}_{t-2}^{*} \\
& +\rho_{3 *}^{\pi \pi} \hat{\pi}_{t-3}^{*}+\rho_{3 *}^{\pi c} \hat{c}_{t-3}^{*}+\rho_{4 *}^{\pi \pi} \hat{\pi}_{t-4}^{*}+\rho_{4 *}^{\pi c} \hat{c}_{t-4}^{*}+\varepsilon_{\pi^{*}, t} .
\end{aligned}
$$

